
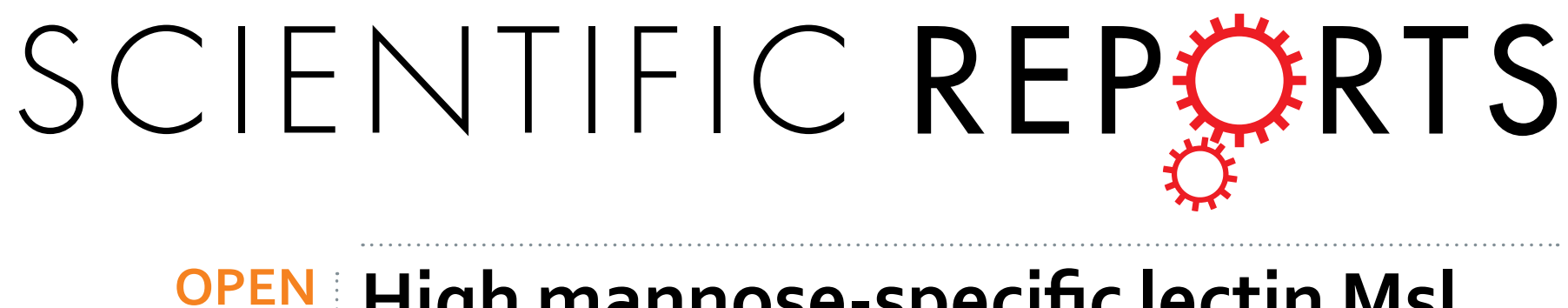

\title{
High mannose-specific lectin Msl mediates key interactions of the vaginal Lactobacillus plantarum
}

Received: 28 July 2016

Accepted: 21 October 2016

Published: 17 November 2016

\section{isolate CMPG5300}

Shweta Malik ${ }^{1,2,{ }^{*}}$, Mariya I. Petrova ${ }^{1,2,{ }^{*}}$, Nicole C. E. Imholz ${ }^{1,2}$, Tine L. A. Verhoeven ${ }^{1}$, Sam Noppen ${ }^{3}$, Els J. M. Van Damme ${ }^{4}$, Sandra Liekens ${ }^{3}$, Jan Balzarini ${ }^{3}$, Dominique Schols ${ }^{3}$, Jos Vanderleyden ${ }^{1}$ \& Sarah Lebeer ${ }^{1,2}$

To characterize the interaction potential of the human vaginal isolate Lactobacillus plantarum CMPG5300, its genome was mined for genes encoding lectin-like proteins. cmpg5300.05_29 was identified as the gene encoding a putative mannose-binding lectin. Phenotypic analysis of a gene knock-out mutant of cmpg5300.05_29 showed that expression of this gene is important for autoaggregation, adhesion to the vaginal epithelial cells, biofilm formation and binding to mannosylated glycans. Purification of the predicted lectin domain of $\mathrm{Cmpg} 5300.05$ 29 and characterization of its sugar binding capacity confirmed the specificity of the lectin for high- mannose glycans. Therefore, we renamed Cmpg5300.05_29 as a mannose-specific lectin (Msl). The purified lectin domain of Msl could efficiently bind to HIV-1 glycoprotein gp120 and Candida albicans, and showed an inhibitory activity against biofilm formation of uropathogenic Escherichia coli, Staphylococcus aureus and Salmonella Typhimurium. Thus, using a combination of molecular lectin characterization and functional assays, we could show that lectin-sugar interactions play a key role in host and pathogen interactions of a prototype isolate of the vaginal Lactobacillus microbiota.

Given the key importance of the urogenital microbiota for human reproduction, increasing efforts are put in place to characterize this microbiome in healthy and pathogenic or unwanted conditions such as bacterial vaginosis (BV) and preterm labor ${ }^{1}$. Compared to microbial communities at other human body sites, the vagina provides an interesting case since dominance by specific bacterial taxa - namely Lactobacillus species- is clearly linked to a healthy state ${ }^{2}$. These lactobacilli appear to promote the protection of the urogenital tract from viral pathogen invasion such as Human Immunodeficiency Virus (HIV) 2,3 and Herpes Simplex virus-2 (HSV-2) ${ }^{4}$, bacterial and yeast pathogens such as Escherichia coli ${ }^{5}$ and Staphylococcus aureus ${ }^{6}$ and Candida albicans ${ }^{7}$, respectively. However, the molecular mechanisms behind the health-promoting effects of vaginal lactobacilli are in general not well known. One of the postulated health benefits of lactobacilli is based on the direct inhibition of pathogens by the production of active compounds such as lactic acid and bacteriocins (Petrova et al. ${ }^{2}$ ). Another mechanism by which lactobacilli are known to prevent infections is by preventing adhesion, invasion and biofilm formation of the pathogens. For example, vaginal lactobacilli have been suggested to be able to prevent and/or treat $E$. coli-associated urinary tract infections (UTI) and aerobic vaginitis ${ }^{8,9}$, but the molecules involved are not well studied. Cell surface molecules of lactobacilli could play a role in pathogen exclusion by (1) competitive binding to the same receptors as pathogens on the host surface, thereby blocking pathogen adhesion or (2) by binding to ligands on the pathogenic surfaces, thereby blocking virulence mechanisms such as invasion and/or promoting enhanced exposure to the secreted antimicrobials of lactobacilli ${ }^{2}$.

${ }^{1} \mathrm{KU}$ Leuven, Centre of Microbial and Plant Genetics, Leuven, Belgium. ${ }^{2}$ University of Antwerp, Department of Bioscience Engineering, Research Group Environmental Ecology and Applied Microbiology, Antwerp, Belgium. ${ }^{3} \mathrm{KU}$ Leuven, Department of Microbiology and Immunology, Rega Institute for Medical Research, Laboratory of Virology and Chemotherapy, Leuven, Belgium. ${ }^{4}$ Ghent University, Department of Molecular Biotechnology, Ghent, Belgium. *These authors contributed equally to this work. Correspondence and requests for materials should be addressed to S.Lebeer (email: sarah.lebeer@uantwerpen.be) 
(a)

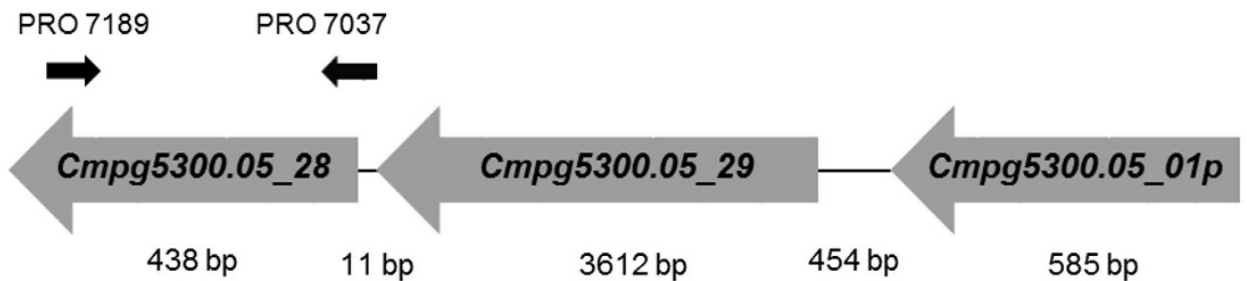

(b)

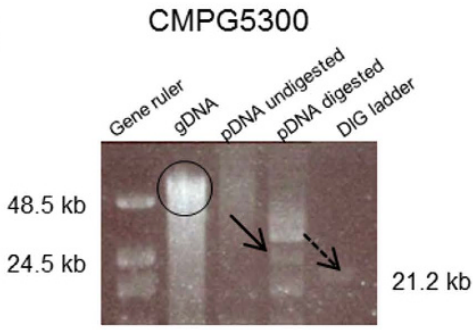

WCFS1

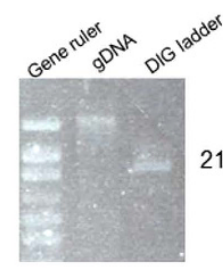

(c)

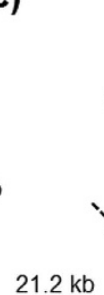

CMPG5300

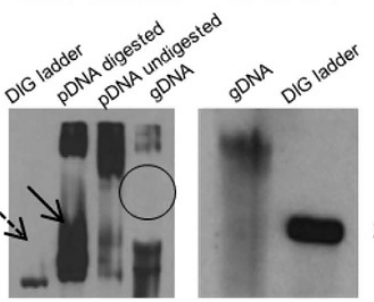

Figure 1. Plasmid location of cmpg5300.05_29. (a) Schematic illustration of the genetic organization of cmpg5300.05_29 on the putative plasmid contig 54. The primer pair PRO 7189 and PRO 7037 (black arrows) was used for constructing the probe for Southern hybridization. (b) Southern blot analysis. DNA gel profile for CMPG5300- Lane Gene ruler: High range ladder; Lane gDNA: Total genomic DNA preparation (band encircled in black); Lane pDNA undigested: Total plasmid DNA preparation-undigested ( $500 \mathrm{ng} / \mathrm{ml})$; Lane pDNA digested: Total plasmid DNA digested with restriction enzymes $(500 \mathrm{ng} / \mathrm{ml})$; Lane DIG ladder: DIG ladder. DNA gel profile for WCFS1- Lane Gene ruler: High range ladder; Lane gDNA: Total genomic DNA; Lane DIG ladder: DIG ladder. (c) Southern blot of CMPG5300- Lane DIG ladder: DIG ladder; Lane pDNA digested: Total plasmid DNA digested (500 ng/ml); Lane pDNA undigested: Total plasmid DNA-undigested (500 ng/ml); Lane gDNA: Total genomic DNA. Southern blot of WCFS1- Lane gDNA: Total genomic DNA; Lane DIG ladder: DIG ladder. Southern hybridization of a 487-bp cmpg5300.05_28-specific labeled fragment gave a binding signal (at a size slightly higher than $21.2 \mathrm{kbp}$ ) marked in black solid arrow (in both DNA gel and Southern blot pictures) with the plasmid DNA preparations indicating the plasmid location of cmpg5300.05_29. No signal was obtained at the position of the total DNA (encircled). On the other hand, the 772-bp labeled fragment of L. plantarum WCFS1 (used as control) yielded a signal corresponding to band of the chromosomal DNA preparation.

Lectins are specific sugar-binding proteins or carbohydrate-binding agents (CBAs). Because of the key role of sugar recognition in many physiological functions, they can be postulated to mediate crucial functions of the human microbiota, including colonization of the host and interaction with pathogens ${ }^{10}$. Yet, they are underexplored in functional microbiota studies. In this study, we investigated the lectin-sugar interaction potential of a vaginal microbiome isolate, Lactobacillus plantarum CMPG5300, for which we recently determined the genome sequence $^{11}$. Genome mining of L. plantarum CMPG5300 resulted in the identification of cmpg5300.05_29 as the gene encoding a putative mannose-binding lectin.

\section{Results}

Identification of the putative lectin-like encoding cmpg5300.05_29 gene on a $\sim 28 \mathrm{~kb}$ plasmid. When we mined the genome sequence of $L$. plantarum CMPG5300 for putative lectin-encoding genes (Malik et al. ${ }^{11}$ ), the sortase-dependent, putative mannose-specific adhesin-encoding gene cmpg5300.05_29 of CMPG5300 was found to be located at the start and the end of a contig (contig 54) indicating the contig was circular, hence a plasmid. The gene cmpg5300.05_29 shows $72 \%$ identity to the mannose specific adhesin ( $m s a$ ) gene $l p \_1229$ of Lactobacillus plantarum WCFS $1^{12}$ at DNA level, while the encoded proteins show $61 \%$ similarity (5e-55). However, Cmpg5300.05_29 is 193 amino acids longer than that of L.plantarum WCFS1 (Lp_1229). The protein consists of a ConA-like domain, classified as a Legume-L type lectin followed by Type I MUB domain and four copies of Type II MUB domains.

Validation of the plasmid location was done experimentally, with PCR and Southern hybridization with various primers mentioned in Table S1 and probes depicted in Fig. 1a. Since the cmpg5300.05_29 gene itself contains a lot of repetitions, we focused on detecting the regulator encoding gene cmpg5300.05_28 located upstream from this sequence. Southern hybridization indeed confirmed the presence of the genes cmpg5300.05_28 and cmpg5300.05_29 mainly in the plasmid DNA samples (Fig. 1b and c). The size of the plasmid hybridizing with cmpg5300.05_28 also corresponds to the size of contig 54 on which cmpg5300.05_29 is located, which is $\sim 28 \mathrm{~kb}$. This plasmid location is unlike the chromosomally-located homologous msa genes in other L. plantarum strains ${ }^{13}$, as confirmed here for L. plantarum strain WCFS1 (Fig. 1b and c). 
(a)

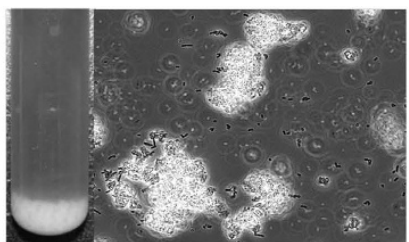

(b)

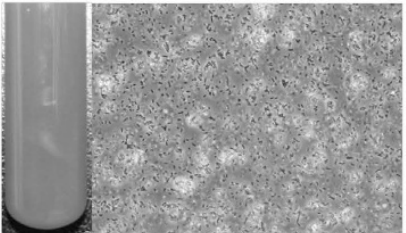

(c)

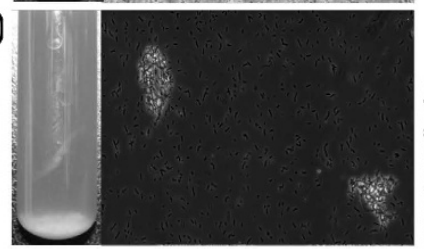

(d)

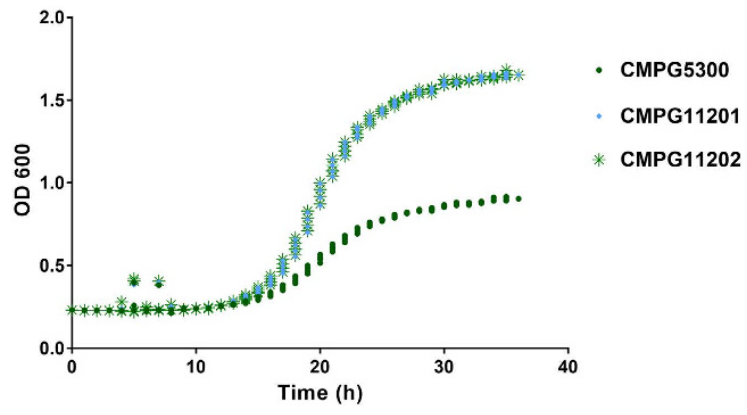

(f) (e)

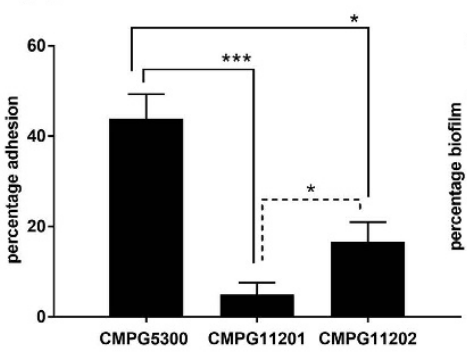

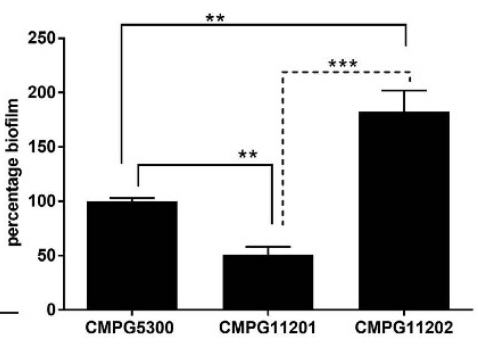

(g)

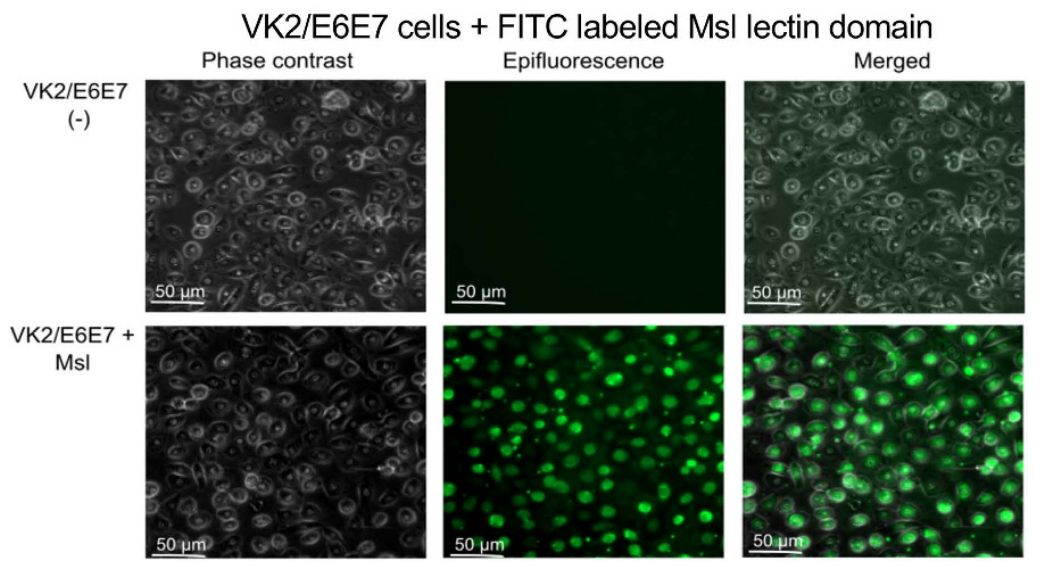

Figure 2. Phenotypic analysis of the mutant strain CMPG11201. (a) Overnight cultures of L. plantarum CMPG5300 (b) its mutant CMPG11201, and (c) complemented strain CMPG11202 in MRS medium. Phasecontrast microscopic images show extensive cell clumps in the case of L. plantarum CMPG5300 (a) and some clumps in the complemented strain CMPG11202 (c), in contrast to the small-sized clusters and mostly single cells that are seen with the mutant CMPG11201 (b). (d) Growth capacity of L. plantarum CMPG5300, CMPG11201 and CMPG11202 mutants in MRS medium. (e) Adhesion capacities of L. plantarum CMPG5300 and CMPG11201 mutant to VK2/E6E7 vaginal epithelial cells. (f) Biofilm formation capacities of L. plantarum CMPG5300 and mutant CMPG11201. The results are expressed relative to the biofilm thickness of L. plantarum CMPG5300 wild-type (positive control), which was set at 100\%. The error bars represent standard deviations of 8 biological repeats. The dataset comparisons (mutant pairwise to wild-type or complemented strain pairwise mutant strain) are considered significant ( $p<0.05$ indicated with one asterisks, $p<0.01$ indicated with two asterisks and $\mathrm{p}<0.001$ indicated with three asterisks in the figure). (g) Binding of the FITC-labelled lectin domain of Msl to VK2/E6E7.

Mutant analysis shows a key role for Cmpg5300.05_29 in auto-aggregation and adhesion. Subsequently, the cmpg5300.05_29 knock-out mutant designated CMPG11201 was constructed by double homologous recombination. This mutant strain CMPG11201 did not display extensive cell clumping, as observed for the wild-type CMPG5300 (Fig. 2a and b). In contrast, the complemented strain CMPG11202 exhibited cell clumps, nonetheless smaller than the wild-type L. plantarum CMPG5300, suggesting that the phenotype was not fully restored (Fig. 2c). Of note, the mutant showed the same growth characteristics as wild-type strain L. plantarum CMPG5300 when grown in MRS (Fig. 2d). L. plantarum CMPG5300 and mutant CMPG11201 were then analyzed for adhesion to the vaginal epithelial cell line VK2/E6E7 (Fig. 2e) and biofilm formation (Fig. 2f) on a polystyrene surface. A significant decrease of $\sim 80$ percent was observed for adhesion and $\sim 50$ percent for biofilm formation in case of the mutant strain CMPG11201 compared to the wild-type. The restoration of the phenotype of the complemented strain CMPG11202 substantiates the role of this lectin in the adhesive and biofilm-forming 
phenotype of the strain (Fig. 2e and f). Of note, the adhesive capacity of the complemented strain was not fully restored to the wild-type level like the biofilm-forming phenotype although it was significantly higher than that of the mutant. To validate the role of Msl in the adhesion capacity of the L. plantarum CMPG5300, the FITClabelled lectin domain of Msl was examined for binding to VK2/E6E7 using fluorescence microscopy. The results show clear binding of the lectin domain of Msl to VK2/E6E7 epithelial cells (Fig. 2g).

Saccharomyces cerevisiae and Candida albicans agglutination assay shows mannan-binding capacity of Cmpg5300.05_29. To obtain a first indication of the sugar specificity of Cmpg5300.05_29, a S. cerevisiae BY4741 agglutination assay was performed, which is a standard assay to explore mannose-binding activity of bacterial lectins ${ }^{14}$. L. plantarum CMPG5300 showed a clear capacity to agglutinate S. cerevisiae, which was independent of the presence of calcium and magnesium ions (data not shown) and this was reduced significantly by addition of methyl- $\alpha$-D-mannopyranoside (Fig. 3a). In contrast, mutant CMPG11201 showed a significant decrease in agglutination (Fig. 3a), while the complemented strain CMPG11202 was also able to agglutinate $S$. cerevisiae to some extent (Fig. 3a). We could corroborate these findings using ELISA where we obtained a significant binding of the wild-type strain CMPG5300 to mannan but a clear loss of binding for the cmpg5300.05_29 mutant (Fig. 3b). To exclude that other cell surface ligands could still interfere with the results in the assay with the mutant strain, we subsequently expressed and purified the lectin domain of Cmpg5300.05_29. Only the predicted lectin domain was expressed in E. coli, as we were unable to express the large-sized protein (encoded by a $\sim 3.6 \mathrm{~kb}$ long gene). The purified lectin domain could also agglutinate S. cerevisiae (Fig. $3 \mathrm{c}$ ) and the related yeast pathogen C. albicans (Fig. 3d), as shown after FITC labeling, providing an indication for the potential interaction of the lectin with pathogens. This agglutination was significantly reduced in the presence of methyl- $\alpha$-D-mannopyranoside (Fig. $3 c$ and d). The L-type lectin domain of lectin-like protein 2 (Llp2) isolated from Lactobacillus rhamnosus GG used as a control did not agglutinate S. cerevisiae and C. albicans (Fig. $3 \mathrm{c}$ and d).

Cmpg5300.05_29 shows specificity for high-mannose $\mathbf{N}$-glycans. To determine the sugar specificity of Cmpg5300.05_29 in a more precise manner, pull-down sugar-binding assays were performed using Sepharose beads coated with various sugar substrates. The well documented mannose-specific Hippeastrum hybrid (amaryllis) lectin (HHA) ${ }^{15}$ was used as a positive control. These experiments showed that the lectin domain of Cmpg5300.05_29 binds more strongly to beads coated with mannan compared to uncoated beads and beads coated with mannose, glucose, fucose or GlcNAc (Fig. 3e).

The glycan array analysis revealed that the lectin domain binds to especially high mannose $\mathrm{N}$-type glycans (Fig. 4a and b, Table S2). These include Man 1 1-2Man $\alpha 1-6($ Man $\alpha 1-3)$ Man $\alpha 1-6($ Man $\alpha 1-2 M a n \alpha 1-2 M a n \alpha$ 1-3) Man $\beta$ 1-4GlcNAc $\beta$ 1-4GlcNAc $\beta$-Sp 12; Man $\alpha$ 1-6(Man $\alpha$ 1-3)Man $\alpha$ 1-6(Man $\alpha$ 1-3) Man $\beta$ 1-4GlcNAc $\beta$

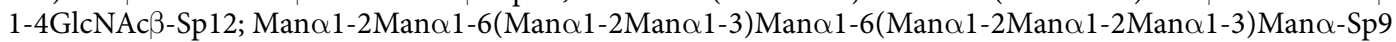

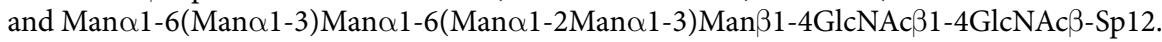

Interaction between Cmpg5300.05_29 and HIV-1 glycoproteins. Since the HIV-1 glycoproteins are enriched in high-mannose $\mathrm{N}$-type glycans ${ }^{16}$, we determined the interaction of L. plantarum CMPG5300 and the lectin domain of Cmpg5300.05_29 with HIV. First, the capacity of CMPG5300 and its mutant derivatives to bind to immobilized HIV-1 gp120 and gp41 was analyzed using an ELISA-based approach. The wild-type strain L. plantarum CMPG5300 showed a significant and specific binding to both gp 120 and gp41 (Fig. 5a and b). Whereas, the mutant CMPG11201 did not show any binding, suggesting that Cmpg5300.05_29 imparts the gp120 and gp41 binding phenotype to L. plantarum CMPG5300. However, the binding to these sugars could not be restored in the complemented strain CMPG11202. Subsequently, we confirmed binding of the lectin domain to HIV-1 gp120 with Surface Plasmon Resonance (SPR) (Fig. 5c). This was reversed by $1 \mathrm{mM}$ man $\alpha(1-3) \mathrm{man} \alpha$ (1-6)man (dotted lines, Fig. 5b), indicating that this trimannose is a competitive inhibitor for binding of the lectin domain to the HIV glycoproteins, and that the lectin domain shows affinity for the $\alpha(1-3) / \alpha(1-6)$ configuration of mannose. The kinetic results show affinities $\left(K_{D}\right)$ in the lower micromolar range (comparable for both gp120 and gp41) (Fig. 5d). Comparison of the binding affinities of the lectin domains of $L$. plantarum CMPG5300 (1.85E-06 $\mathrm{M})$ and L.plantarum WCFS1 (6.26E-06 M) (Table 1) indicates that the lectin domain of L. plantarum CMPG5300 shows a higher affinity to both HIV-1 gp120 and gp41, than that of $L$. plantarum WCFS1, which is not a vaginal isolate. However, HHA (used as a positive control) shows a 1,000-fold higher affinity (or 1,000-fold lower $\mathrm{K}_{\mathrm{D}}$ ) $(1.32 \mathrm{E}-09 \mathrm{M})$ for the viral envelope glycoproteins.

Given the binding capacity of the lectin domain to HIV-1 gp120 (and gp41) observed in the SPR experiments, it was of interest to determine its capacity to inhibit HIV-1 infection in cell culture. However, addition of the purified lectin domain even up to a concentration of $200 \mu \mathrm{g} / \mathrm{ml}$ was not sufficient to measurably inhibit HIV-1 infection in human CD4+ T-lymphocytic C8166 cell and Raji DCSIGN cultures under our experimental conditions where HHA and GRFT were clearly inhibitory at concentrations less than $1 \mu \mathrm{g} / \mathrm{ml}$ (data not shown).

Anti-biofilm activity of the lectin domain of Cmpg5300.05_29 against common urogenital bacterial pathogens. We subsequently focused on the potential of Cmpg5300.05_29 for preventing bacterial infections by investigating its role in inhibiting bacterial biofilms. When the purified lectin domain of Cmpg5300.05_29 was added to biofilm cultures of uropathogenic Escherichia coli UTI89 at the onset of biofilm development $(t=0 \mathrm{~h})$, it significantly inhibited biofilm formation of the pathogen by 80 to 90 percent at $50 \mu \mathrm{g} / \mathrm{ml}$ and $200 \mu \mathrm{g} / \mathrm{ml}$, respectively (Fig. $6 \mathrm{a}$ ). When added after $1.5 \mathrm{~h}$ or $24 \mathrm{~h}$ of biofilm development, it could reduce biofilm formation up to 60 percent compared to the control, indicating that it could also interfere with the later steps of biofilm formation (Fig. 6a). To corroborate the specific activity of Cmpg5300.05_29, ConA and HHA, well-known mannose-specific plant lectins, were also investigated for their activity against E. coli UTI89 
(a)

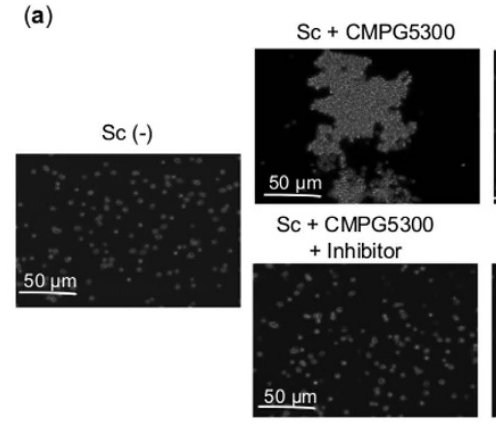

(c)
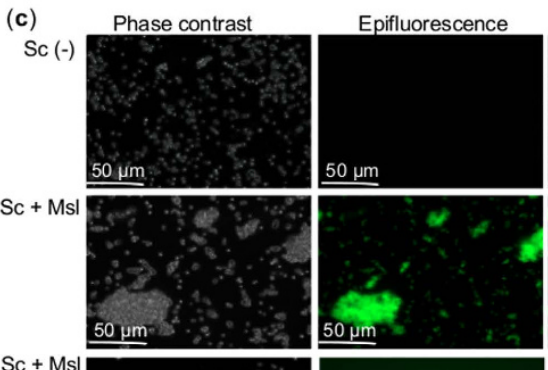

Epifluorescence

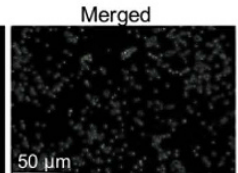

$\mathrm{Sc}+\mathrm{Msl}$
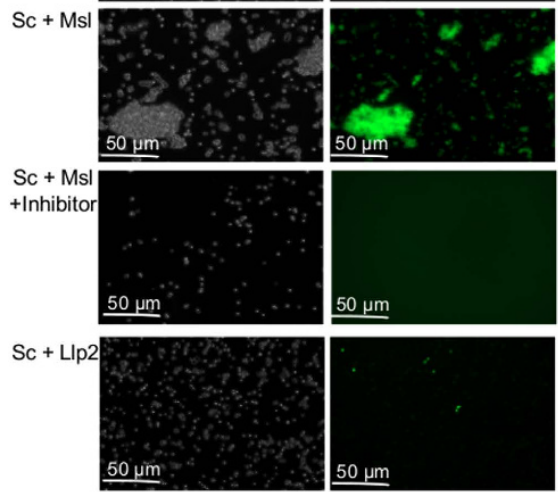

(e)

$75 \mathrm{kDa}$
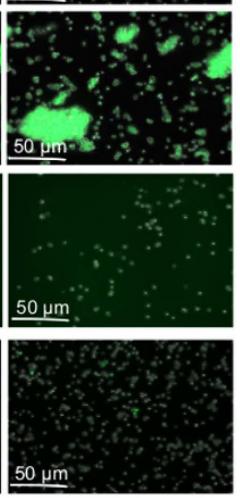

$25 \mathrm{kDa}$

tD of CMPG5300.05_29
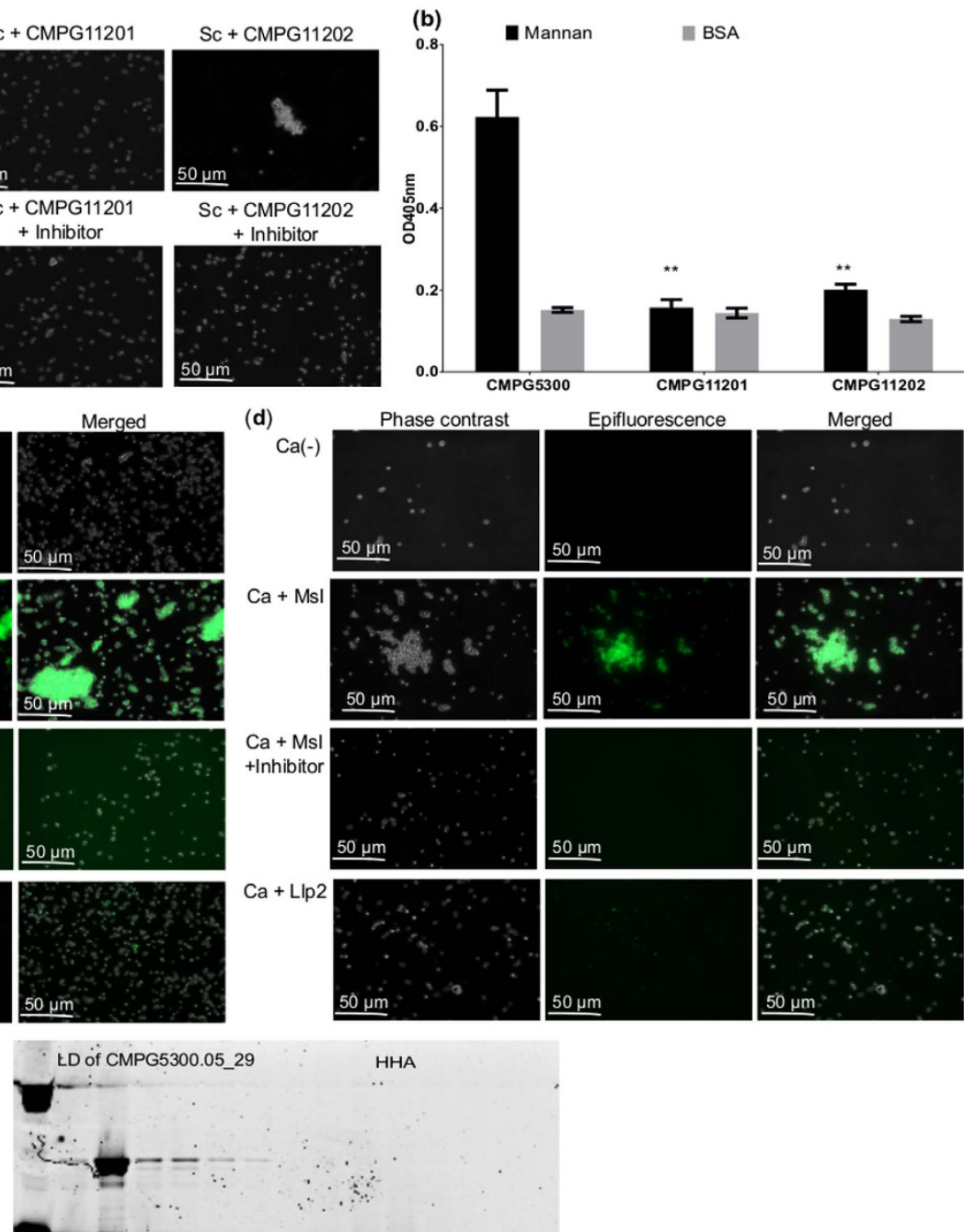

$\mathrm{Ca}+\mathrm{Llp} 2$
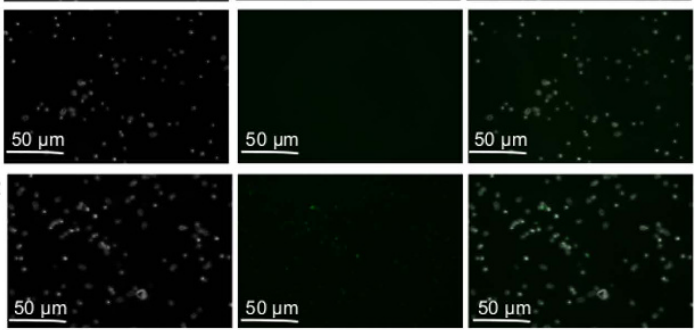

HHA
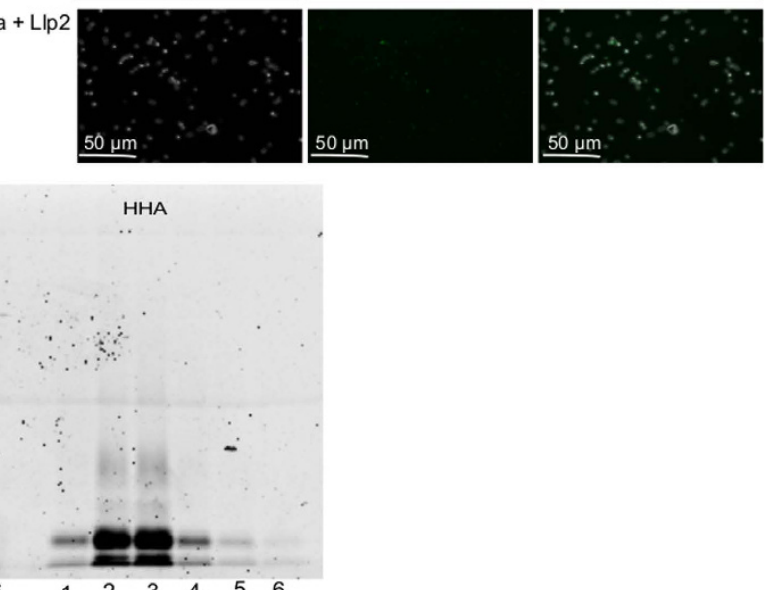

Figure 3. Agglutination assay of L. plantarum CMPG5300, its mutant derivatives and the lectin domain of Compg5300.05_29 with S. cerevisiae and C. albicans. (a) Phase contrast images of the agglutination assay of $S$. cerevisiae BY4741 (Sc) incubated with L. plantarum CMPG5300, CMPG11201 mutant and CMPG11202 mutant alone and in the presence of methyl- $\alpha$-D-mannopyranoside inhibitor. For each strain and condition tested, the experiment was performed at least three times. The images shown are representative of at least five imaging fields. (b) Binding of biotin-labeled cells of the wild-type strain L. plantarum CMPG5300, mutant CMPG11201 and complemented strain CMPG11202 to yeast mannan. The OD at $405 \mathrm{~nm}$ reflects the binding efficiency of the bacterial strains. BSA was used as a negative control. The dataset comparisons (mutant pairwise to wildtype) are considered significant ( $\mathrm{p}<0.01$ indicated with two asterisks in the figure). The dataset comparison (complemented mutant pairwise to the mutant strain) show no significant differences. (c) Fluorescent images of the agglutination assay of S. cerevisiae BY4741 (Sc) and (d) C. albicans SC5314 (Ca) in the presence of the FITC labeled lectin domain of Cmpg5300.05_29, FITC labeled lectin domain of Cmpg5300.05_29 in the presence of methyl- $\alpha-D$-mannopyranoside and lectin-like protein 2 (Llp2) from L. rhamnosus GG used as control. For each strain and condition tested, the experiment was performed at least three times. The images shown are representative of at least five imaging fields. (e) Proteins that bound to uncoated sepharose beads (lane 1, used as negative control), sepharose beads coated with various sugars: mannan (lane 2), mannose (lane 3), glucose (lane 4), fucose (lane 5), GlcNAc (lane 6) as separated by SDS-PAGE. The first six lanes (LD of CMPG5300.05_29) represent the lectin domain of CMPG5300.05_29 and the next six lanes represent HHA (used as control).

biofilms but no inhibition was observed (Fig. 1Sa). In addition, since E. coli UTI89 biofilm formation is based on mannose-specific binding of FimH fimbria, we used D-mannose as a competitive inhibitor in the assay and 


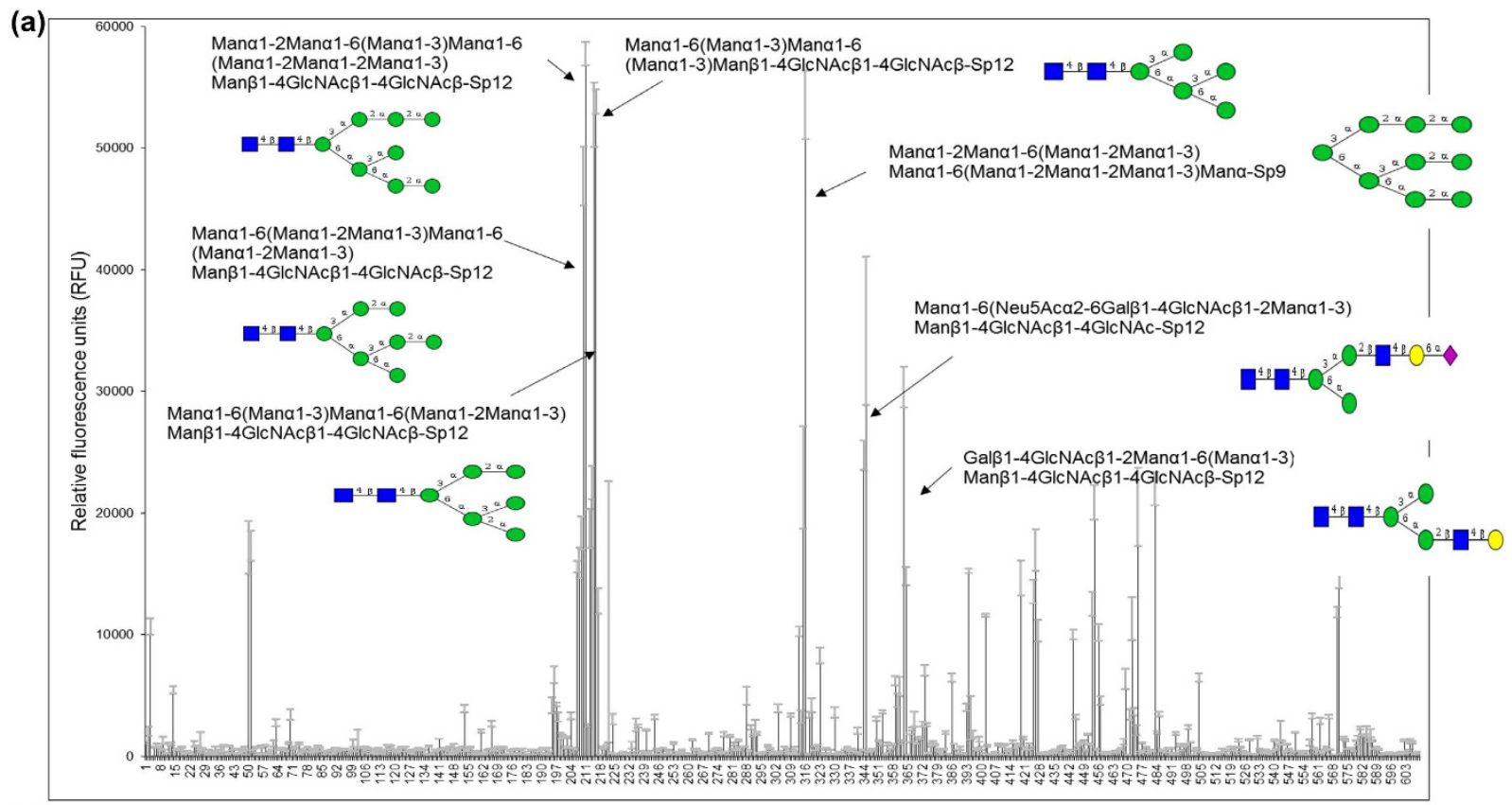

(b)

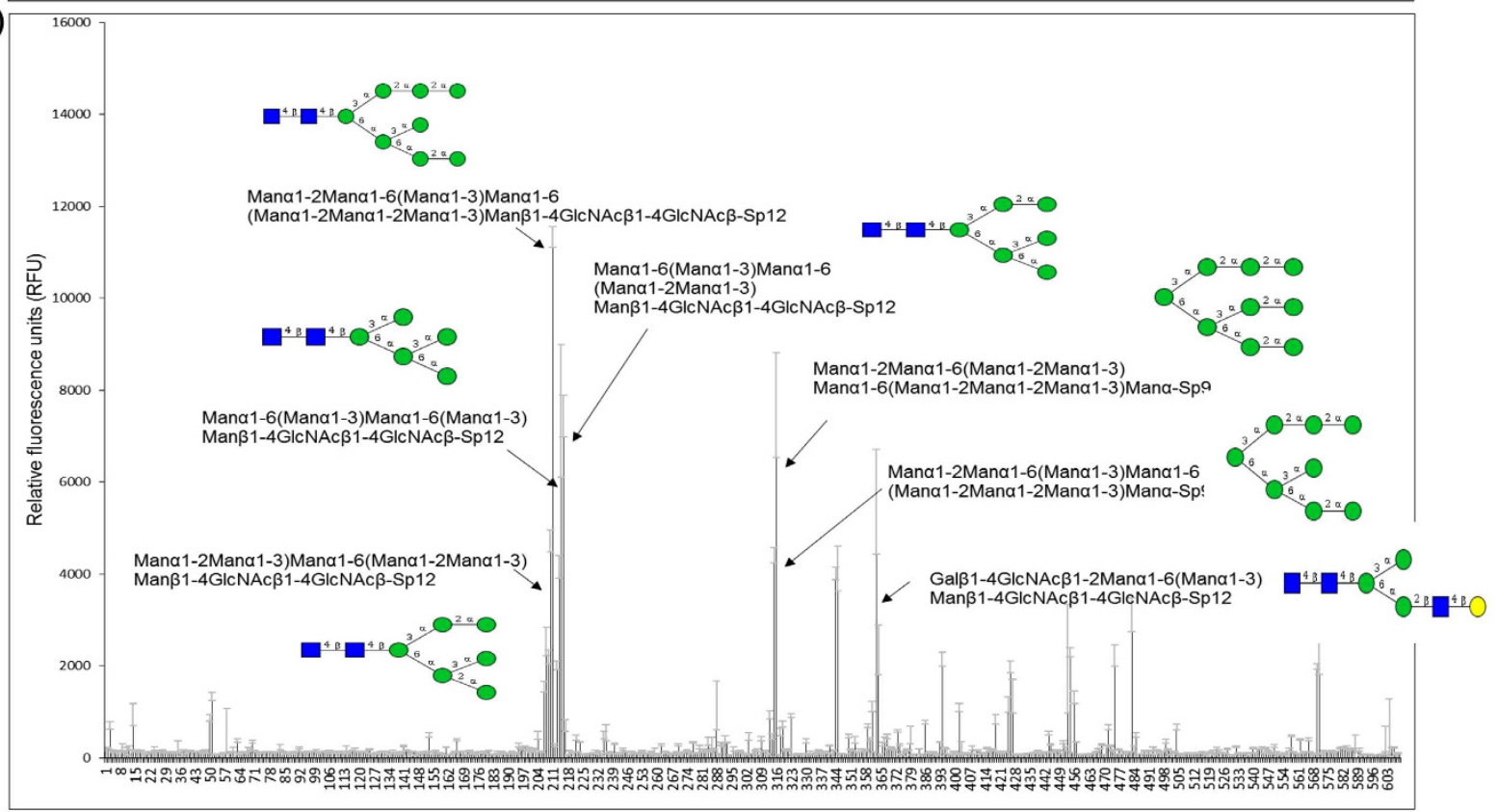

Figure 4. Glycan array analysis. (a) Binding capacity of $200 \mu \mathrm{g} / \mathrm{ml}$ of the lectin domain of Msl to highmannose glycans. (b) Binding capacity of $20 \mu \mathrm{g} / \mathrm{ml}$ of the lectin domain of Msl to high-mannose glycans as depicted with black arrows in the figure (the structure of the glycans printed on the array can be find on the webpage of the CFG, www.functionalglycomics.org) and in Table S2.

again, no inhibition of biofilm formation was observed (Fig. 1Sa). Of note, we could not find any effect of the lectin on the planktonic growth of E. coli UTI89 under the same growth conditions as during the biofilm formation (Fig. 6b), indicating that the inhibition is biofilm-dependent. To explore how the lectin domain structurally interferes with E. coli UTI89 biofilm formation, microscopic analyses of the biofilms incubated with the lectin were performed. The results show that addition of FITC-labeled lectin domain of Cmpg5300.05_29 at the onset of the biofilm at concentration $50 \mu \mathrm{g} / \mathrm{ml}$ led to the formation of large holes in the biofilm (Fig. $6 \overline{\mathrm{d}}$ ), as compared to the negative control where dense biofilms were seen (Fig. 6c). The lectin domain of Cmpg5300.05_29 was also dispersed within the biofilm (Fig. 6d).

The lectin domain of Cmgp5300.05_29 subsequently showed the capacity to inhibit biofilm formation by Staphylococcus aureus, a pathogen causing the fatal toxic shock syndrome, with an average biofilm reduction up to 36 percent in the case of $S$. aureus strain SH1000 and 41 percent in the case of $S$. aureus Rosenbach when added at the onset of the biofilm $(\mathrm{t}=0 \mathrm{~h})$ (Fig. 6e). However, when it was added after $1.5 \mathrm{~h}$ or $24 \mathrm{~h}$ of biofilm development, 
(a)

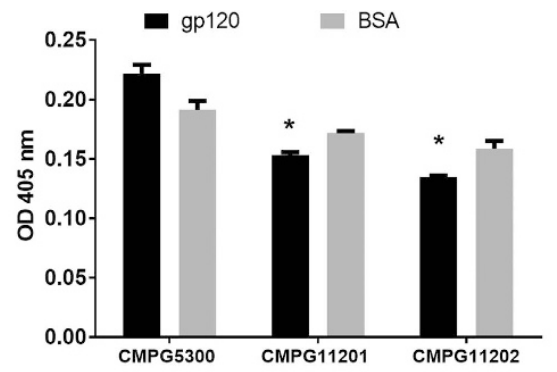

(b)

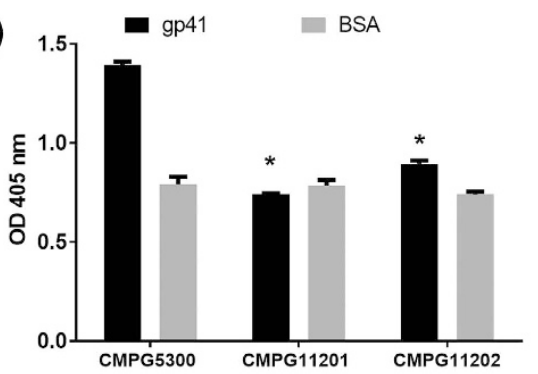

(c)

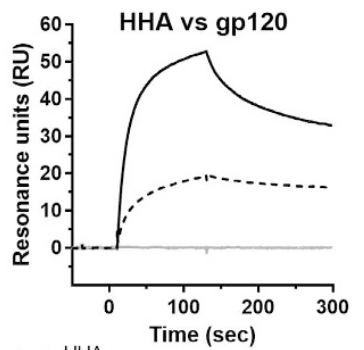

- HHA Time (sec)

-.. HHA + trimannose

- trimannose

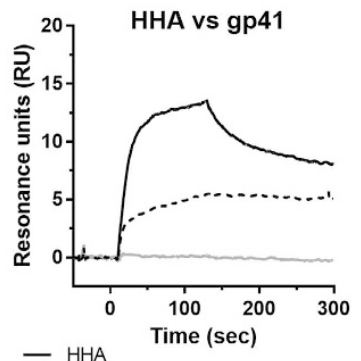

- HHA

-.. HHA + trimannose

- trimannose

(d)
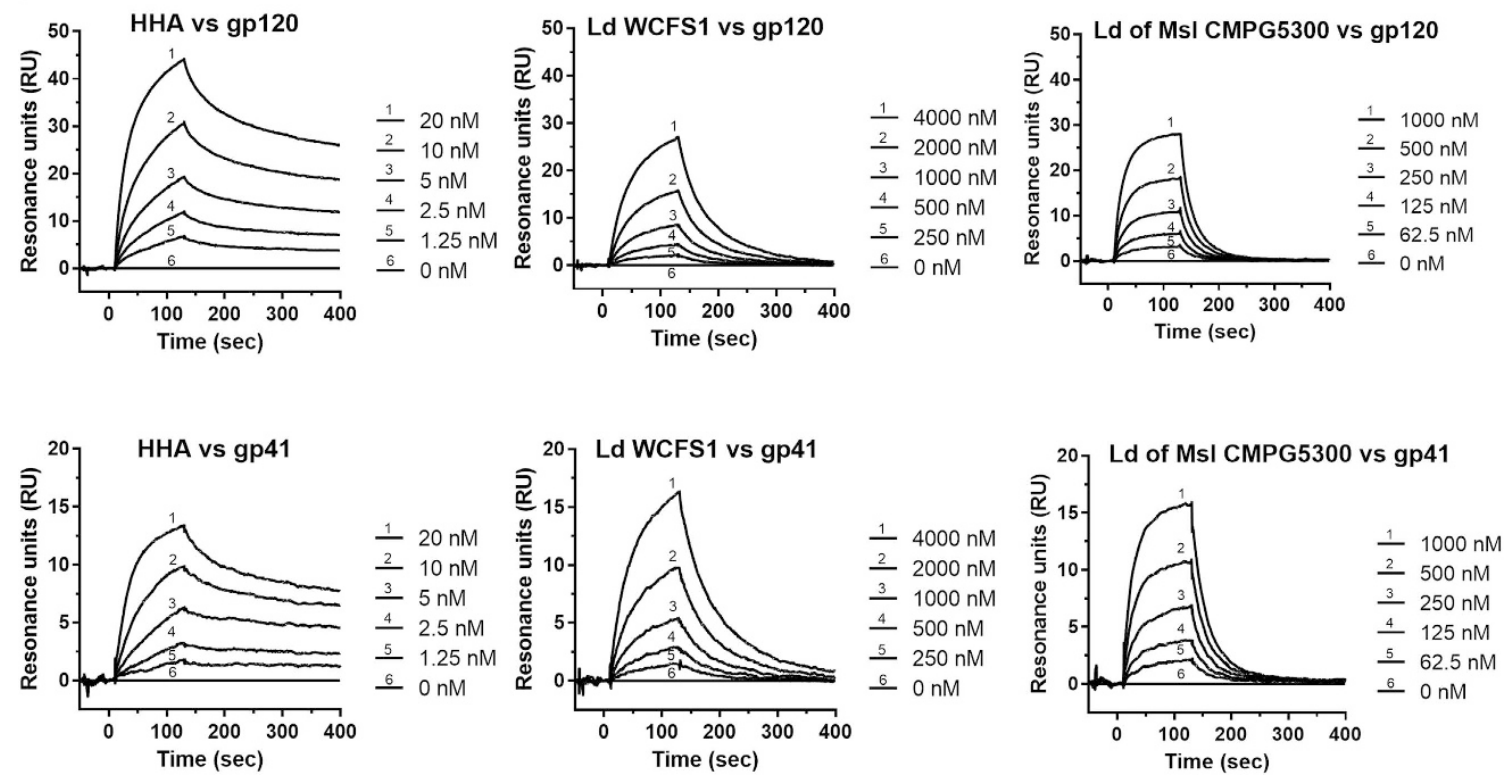

Figure 5. HIV-1 gp120 and gp41 binding of bacterial cells and the purified lectin domain of

Cmpg5300.05_29. (a) Binding of biotin-labeled cells of the wild-type strain L. plantarum CMPG5300, mutant CMPG11201 and complemented strain CMPG11202 to HIV-1 gp120. The OD at $405 \mathrm{~nm}$ reflects the binding efficiency of the bacterial strains. BSA was used as a negative control. (b) Binding of biotin-labeled cells of the wild-type strain L. plantarum CMPG5300, mutant CMPG11201 and complemented strain CMPG11202 to HIV-1 gp41. The OD at $405 \mathrm{~nm}$ reflects the binding efficiency of the bacterial strains. BSA was used as a negative control. (c) Binding of the lectin domain of CMPG5300 (Ld CMPG5300) to HIV-1 gp120 (solid lines) and 
HIV-1 gp41 (solid lines) in terms of Resonance units as analyzed via SPR. The purified lectin domain of Msa of L. plantarum WCFS1 (Ld WCFS1) was used as control (solid lines) and HHA was used as positive control (solid lines). Upon addition of competitor trimannose $\operatorname{Man} \alpha(1-3) \operatorname{Man} \alpha(1-6)$ Man to the lectin domains, binding to HIV-1 gp120 was abolished (dotted lines). The concentrations of the lectins used are $20 \mathrm{nM}, 4 \mu \mathrm{M}$ and $1 \mu \mathrm{M}$ for HHA (left), lectin domain of Msa of L. plantarum WCFS1 (centre) and lectin domain of CMPG5300.05_29 of CMPG5300 (right), respectively. A concentration of $1 \mathrm{mM}$ was used for trimannose. (d) Kinetic analysis for the interaction of the lectin domain of CMPG5300.05_29 with HIV-1 gp120 and gp41 using the lectin domain of Msa and HHA as control. Serial two-fold analyte dilutions (covering a concentration range from 0 to $20 \mathrm{nM}$ for HHA, 0 to $4000 \mathrm{~nm}$ for Ld WCFS1 and from 0 to $1000 \mathrm{nM}$ for Ld CMPG5300) were injected over the surface of the immobilized gp120 and gp41. A 1:1 binding model was applied to determine the kinetic parameters. The biosensor chip density was 115 RUs for gp120 and 45 RUs for gp41. The dataset comparisons (mutant pairwise to wild-type) are considered significant $(\mathrm{p}<0.05$ indicated with one asterisks). The dataset comparison (complemented mutant pairwise to the mutant strain) show no significant differences.

\begin{tabular}{|l|c|c|c|c|c|c|}
\hline \multirow{2}{*}{} & \multicolumn{3}{|c|}{ HIV-1 gp120 } & \multicolumn{3}{c|}{ HIV-1 gp41 } \\
\cline { 2 - 7 } & $\mathbf{k a}(\mathbf{1} / \mathbf{M s})$ & $\mathbf{k d}(\mathbf{1} / \mathbf{s})$ & KD $(\mathbf{M})$ & $\mathbf{k a}(\mathbf{1} / \mathbf{M s})$ & $\mathbf{k d}(\mathbf{1} / \mathbf{s})$ & KD $(\mathbf{M})$ \\
\hline HHA & $1.66 \mathrm{E}+06$ & $2.19 \mathrm{E}-03$ & $1.32 \mathrm{E}-09$ & $2.75 \mathrm{E}+06$ & $2.29 \mathrm{E}-03$ & $8.36 \mathrm{E}-10$ \\
\hline Lectin domain of Msa & $2.62 \mathrm{E}+03$ & $1.64 \mathrm{E}-02$ & $6.26 \mathrm{E}-06$ & $7.15 \mathrm{E}+03$ & $2.36 \mathrm{E}-02$ & $3.30 \mathrm{E}-06$ \\
\hline Lectin domain of Msl & $3.05 \mathrm{E}+04$ & $5.64 \mathrm{E}-02$ & $1.85 \mathrm{E}-06$ & $2.29 \mathrm{E}+04$ & $2.88 \mathrm{E}-02$ & $1.62 \mathrm{E}-06$ \\
\hline
\end{tabular}

Table 1. Kinetic data for the interaction of the lectin domain of L. plantarum CMPG5300 with HIV-1 gp120 and gp41. ka: association rate constant, kd: dissociation rate constant and $\mathrm{KD}$ : the binding affinity values.

there was no significant anti-biofilm activity, indicating that for these pathogens the inhibition of biofilm formation is merely at the initial stage of adhesion. Bioscreen results showed no effect of the lectin domain on the planktonic growth of either strain (Fig. 6f).

Anti-biofilm activity of the lectin domain of Cmpg5300.05_29 against non-urogenital pathogens. As for urogenital pathogens, various biofilm assays were also performed with the gastrointestinal pathogen Salmonella Typhimurium ATCC14028 and the opportunistic pathogen Pseudomonas aeruginosa. When the purified domain was added at a concentration of 50 and $200 \mu \mathrm{g} / \mathrm{ml}$ at the start of the static peg biofilm assay $(\mathrm{t}=0 \mathrm{~h})$, it led to a significant reduction in biofilm formation by an average of 78 percent (Fig. $7 \mathrm{a}$ ) for $S$. Typhimurium, but not for P. aeruginosa PA14 (Fig. S1 b). No effect was seen when it was added in the later phases of biofilm development (Fig. 7a). Figure 7b demonstrates that even the planktonic growth was not impaired by the lectin domain of Cmpg5300.05_29. Similar to the assay of E. coli UTI89, the effect of ConA, HHA, and D-mannose (used as controls) against Salmonella Typhimurium ATCC14028 biofilms was also investigated where no inhibition was observed (Fig. 1Sa).

Furthermore, microscopic analyses of $S$. Typhimurium biofilms showed that the addition of FITC-labeled lectin domain of Cmpg5300.05_29 at the onset of the biofilm also resulted in the formation of large holes in the biofilm with the lectin domain of Cmpg5300.05_29 dispersed within the biofilm (Fig. 7c and d).

\section{Discussion}

In this study, we genetically and biochemically identified and characterized a $127 \mathrm{kDa}$ mannose-specific lectin Msl from a vaginal Lactobacillus isolate. The lectin was shown to mediate vaginal niche-related functions for L. plantarum CMPG5300 including adhesion to vaginal epithelial cells and auto-aggregation. In addition, the lectin domain showed the ability of structurally inhibiting biofilm formation by various pathogens, as well as a unique interacting capacity with yeast pathogens and viral envelope glycoproteins.

Combining mutant bacterial strains, purified proteins and lectin assays, we could clearly substantiate the high-mannose specificity of Msl. Inhibition of yeast agglutination with methyl-mannopyranoside, loss of mannan-binding capacity observed for the $m s l$ mutant, binding of the purified lectin domain to mannose-coated Sepharose beads, binding signal obtained with high-mannose $\mathrm{N}$-glycans in the glycan array and competitive inhibition of HIV-1 gp120-binding by a trimer of mannose, all validate the specificity of our L. plantarum lectin to (oligo)mannoses. The fact that the lectin domain is even able to agglutinate yeast cells suggests that each lectin domain may bind to several ligands which can be also be predicted from its sequence to form dimmers/ tetramers. This study reports on the detailed and unambiguous characterization of a lectin from a human vaginal Lactobacillus member with detailed glycan array studies showing clear sugar-binding activities. Glycan arrays have been implemented for the determination of the sugar specificity for only a limited number of putative bacterial lectins. For example, the soluble lectin from P. aeruginosa LecB (known as PA-IIL) has been shown to bind strongly to a large variety of fucosylated oligosaccharides, such as $\alpha$-Fuc 1-2 Gal and $\beta-G a l$ 1-4 $\alpha$ (Fuc1-3) $\mathrm{GlcNAc}^{17}$. The FimH adhesin located at the tip of type 1 pili of the uropathogenic E. coli (UPEC) play a role in attachment to urothelium by binding to mannosylated glycoreceptors ${ }^{18}$. Furthermore, to the best of our knowledge, only one other L-type bacterial lectin, known as SraP, has been characterized ${ }^{19}$. SraP isolated from S. aureus was shown to have a high specificity for $\mathrm{N}$-acetylneuraminic acid, as determined by SPR analyses, but not by glycan array, and appears to play an important role in the adhesion of the strain to human respiratory epithelial cells. 
Intriguingly, the lectin-encoding msl gene, as determined by Southern blot hybridization, was found to be encoded by one of the plasmids of L. plantarum CMPG5300. To our knowledge, plasmid-encoded adhesins have so far not often been reported in lactobacilli except for a study on the probiotic intestinal strain $L$. paracasei NFBC338 which encodes for a collagen-binding protein (CD00222) on one of its plasmids ${ }^{20}$. In contrast, plasmid-encoded adhesins and virulence factors that are well-characterized are found especially in enteropathogenic strains such as Yersinia and Salmonella ${ }^{21}$. The plasmid location of the msl gene could suggest that it is a recently acquired property of $L$. plantarum CMPG5300 through horizontal gene transfer. This transfer might have promoted the adaptation of strain CMPG5300 to the vaginal niche, as reflected by our functional assays.

The first niche-related function identified for Msl is its capacity to promote self-aggregation of L. plantarum CMPG5300. Self-aggregation is postulated to increase the colonization potential of lactobacilli in environments with short residence times ${ }^{22}$. Auto-aggregation has been documented before for other vaginal Lactobacillus strains ${ }^{4,23}$ but without details on the molecules involved. We previously observed a loss of auto-aggregation in the sortase A (srtA) mutant ${ }^{24}$. The fact that the $m s l$ mutant of $L$. plantarum CMPG5300 is also clearly impaired in auto-aggregation now shows a role for the sortase-dependent Msl lectin in the auto-aggregation of this strain. Furthermore, we could substantiate a role for the Msl sortase-dependent protein (SDP) in adhesion of this bacterium to the vaginal VK2/E6E7 cell line. This is in agreement with our previous observations that showed a significant decrease in adhesion of the sortase mutant to the VK2/E6E7 cell line ${ }^{24}$. Even though this phenotype was restored in the complemented strain, the auto-aggregating and the adhesive capacities were observed to be reduced when compared with the wild-type. This is in accordance with the results of the complemented srt $A$ strain CMPG5378 (Malik et al. ${ }^{24}$ ) where the phenotype could not be restored to the wild type level. This could partly be due to the copy number effect where the copy number of Cmpg5300.05_29 on the endogenous plasmid of CMPG5300 is different than the one on CMPG11202. Former work on the adhesive factors of vaginal Lactobacillus strains has indicated the involvement of glycoproteins in Lactobacillus acidophilus and Lactobacillus gasseri, carbohydrates in Lactobacillus jenseni ${ }^{25}$ and a non-secretory substance in Lactobacillus crispatus CTV-0 $05^{26}$. However, it remains to be determined whether a related lectin mediates the adhesion in these other vaginal strains as well. For the strain L. plantarum CMPG5300, further functional characterization of the msl mutant also substantiates a role for the Msl lectin in biofilm formation. This phenotype is probably directly linked to the role of Msl in auto-aggregation as a first step in biofilm formation.

High-mannose N-type glycans are found on the glycoproteins of HIV-1 especially on its glycoprotein gp $120^{27}$. The use of CBAs is thus currently explored as a novel microbicidal strategy to prevent HIV infection in the vagina $^{28}$. We observed that Msl has the capacity to interact with the high-mannose envelope glycoprotein of the pathogen HIV. While wild-type L. plantarum CMPG5300 clearly bound to the HIV glycoprotein gp120 (based on ELISA), the $m s l$ mutant significantly lost this binding capacity. In addition, the purified lectin domain exhibited a strong gp120 binding capacity, as determined by SPR analyses, which could be blocked in the presence of an oligomer of mannose. Of note, the mannosylation of gp120 closely resembles the glycans to which Msl shows the strongest binding (Man $\alpha 1-2 M a n \alpha 1-6($ Man $\alpha 1-3)$ Man $\alpha 1-6($ Man $\alpha 1-2 M a n \alpha 1-2 M a n \alpha 1-3) M a n \beta 1-4 G l c N A c \beta$ 1-4GlcNAc $\beta$-Sp12). Some mannose-binding plant lectins are known to have anti-HIV activity by virtue of their specific binding to the highly mannosylated glycoprotein gp $120^{27}$. Moreover, mannose-binding lectin (MBL) detected in vaginal secretions of women was found to be antimicrobial in nature and its deficiency is associated with the recurrence of infections by C. albicans ${ }^{29}$. The present study characterizes an HIV-1 gp120 binding lectin from a Lactobacillus strain. However, we were not able to observe anti-HIV-1 activity in vitro in the standard cellular assays at the tested concentrations (up to $200 \mu \mathrm{g} / \mathrm{ml}$ ) of the lectin domain. This may indicate that the Msl lectin domain binds to gp120 in a non-neutralizing manner like some antibodies, as documented previously ${ }^{30}$. Alternatively, the lectin may be quickly inactivated in the cell culture due to the presence of proteases in the bovine serum-containing medium or to the presence of serum sugars that bind (neutralize) the bacterial lectin. Since the Msl lectin is normally presented on live L. plantarum CMPG5300 cells and this configuration is probably important in vivo for pathogen interaction of these lactobacilli in the vaginal niche, we believe that the lack of efficacy observed in these in vitro assays should not exclude further exploration of the trapping of HIV by lectins/live lactobacilli. Such trapping could eventually eliminate the virus from the vaginal environment by the vaginal fluid in vivo since lectin-mediated binding of vaginal lactobacilli to pathogens could expose the latter to the antimicrobial compounds secreted by lactobacilli, including lactic acid. However, experimental substantiation of such in vivo activity for specific lectins and lactobacilli is severely hampered by the difficulty of animal models for $\mathrm{HIV}^{31}$, although some progress is being made ${ }^{32}$.

Since it can be envisaged that it is more difficult to inhibit invasion of small viral particles compared to larger bacteria, we subsequently focused on the possible role of Cmpg5300.05_29 in preventing bacterial infections by investigating its role in inhibiting bacterial biofilms. Recurrent biofilms are a major problem in urogenital infections ${ }^{33}$. Our results show that the lectin domain of Msl has a remarkable capacity to prevent UPEC and $S$. Typhimurium biofilm formation, as well as moderately affect biofilms of $S$. aureus strains. Previous studies have reported the ability of probiotic lactobacilli to interfere with pathogenic biofilms ${ }^{34-36}$, but without identifying the underlying mode of action. Our findings show the inhibitory capacity of a bacterial, and more specifically a Lactobacillus lectin, against bacterial pathogens. The localization of Msl within pathogenic biofilms as observed after FITC-labeling suggests that the lectin interacts with components of the biofilm matrix, composed of extracellular polymeric substances, including polysaccharides, proteins such as fimbriae and lectins, DNA and lipids ${ }^{37}$ and interferes with stabilization of the biofilm. The composition of the biofilm matrix varies among strains, which may also explain the observed species-specific activity of the lectin against various species. For example, both $S$. Typhimurium and E. coli biofilm matrices contain the polysaccharides cellulose ( $\beta-1,4$-D-glucose polymer) and colanic acid (heteropolysaccharide of glucose, galactose, fucose and glucuronic acid) ${ }^{38,39}$, which can be a target for Msl. The substantiation of biofilm-inhibiting effect using in vivo studies including competitive exclusion is worth further exploration, given the prevalence of problems associated with biofilms and the increased resistance of 
(a)

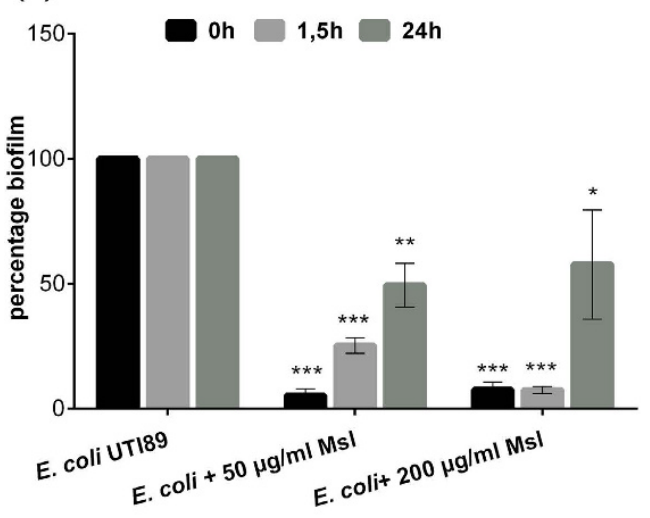

(b)

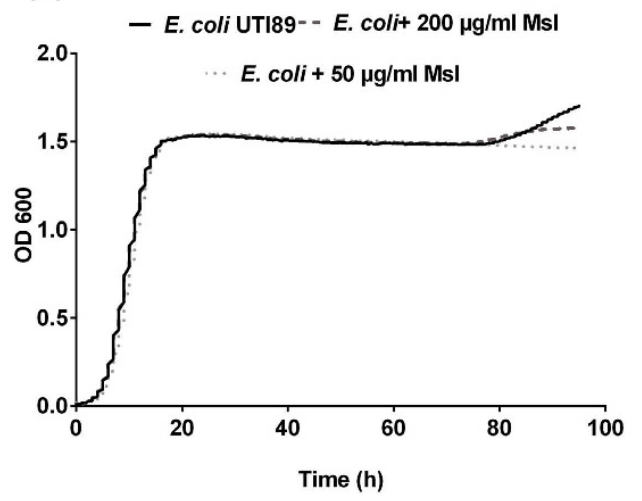

(c)
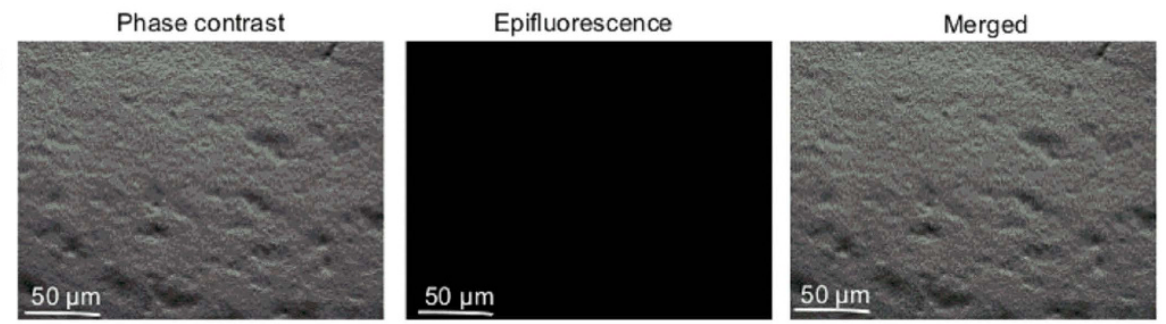

(d)
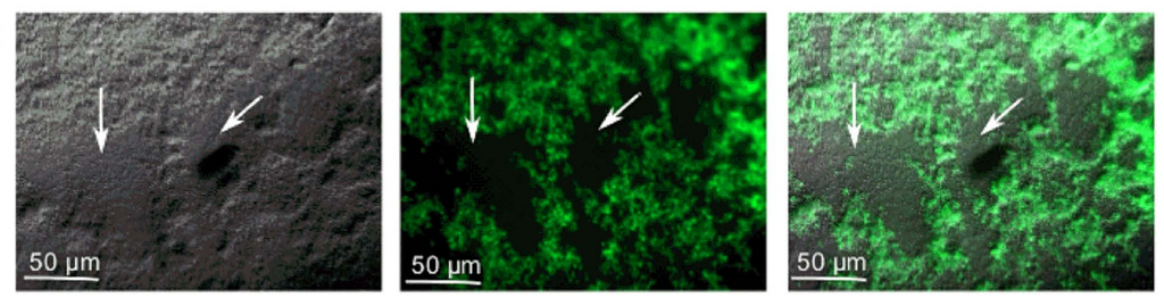

(e)

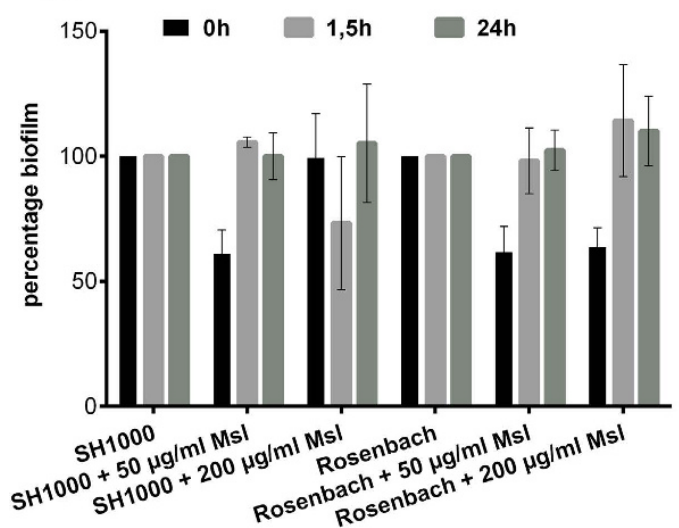

(f) $-\mathrm{SH} 1000$

- Rosenbach

- - SH1000+200 $\mu \mathrm{g} / \mathrm{ml} \mathrm{Msl} \mathrm{-} \mathrm{-} \mathrm{Rosenbach} \mathrm{+} 200 \mu \mathrm{g} / \mathrm{ml}$ Msl

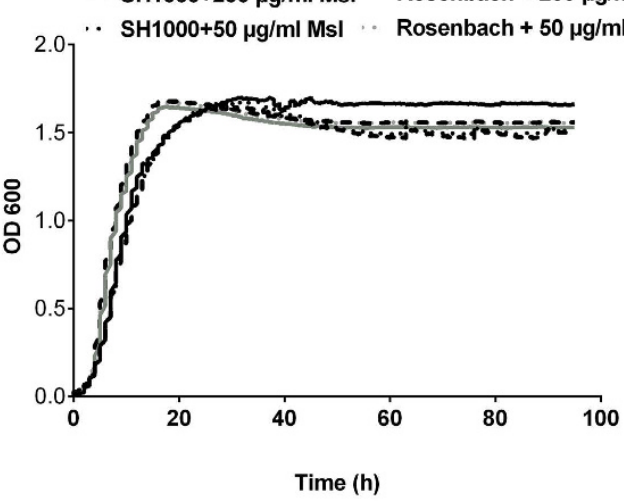

Figure 6. Activity of the lectin domain of Cmpg5300.05_29 against E. coli UTI89, S. aureus SH1000 and Rosenbach. (a) Anti-biofilm activity of the lectin domain of Cmpg5300.05_29 against E. coli UTI89 expressed as percentage inhibition of biofilm formation. The purified lectin domain of Cmpg5300.05_29 was added after $0,1.5$ and $24 \mathrm{~h}$ to the biofilms at a concentration of $50 \mu \mathrm{g} / \mathrm{ml}$ and $200 \mu \mathrm{g} / \mathrm{ml}$. (b) Growth of E. coli UTI89 in TSB in the presence of lectin domain of Cmpg5300.05_29 added at $50 \mu \mathrm{g} / \mathrm{ml}$ and $200 \mu \mathrm{g} / \mathrm{ml}$. (c) Microscopic images of E. coli UTI89 biofilms grown only in $1 / 20 \mathrm{TSB}$ and (d) with $50 \mathrm{\mu g} / \mathrm{ml}$ of FITC-labeled lectin domain of Cmpg5300.05_29. Holes in the biofilms are indicated with arrows. (e) Anti-biofilm activity of the lectin domain of Cmpg5300.05_29 against S. aureus SH1000 and Rosenbach. The purified lectin domain of Cmpg5300.05_29 was added after $0,1.5$ and $24 \mathrm{~h}$ to the biofilms at concentration of $50 \mu \mathrm{g} / \mathrm{ml}$ and $200 \mu \mathrm{g} / \mathrm{ml}$. (f) Growth of $S$. aureus SH1000 and Rosenbach in TSB in presence of lectin domain of Cmpg5300.05_29 added at 50 $\mu \mathrm{g} / \mathrm{ml}$ and $200 \mu \mathrm{g} / \mathrm{ml}$. The dataset comparisons (biofilm formation with addition of lectin to biofilm without adding lectins) are considered significant ( $\mathrm{p}<0.05$ indicated with one asterisks, $\mathrm{p}<0.01$ indicated with two asterisks and $\mathrm{p}<0.001$ indicated with three asterisks in the figure). 
(a)

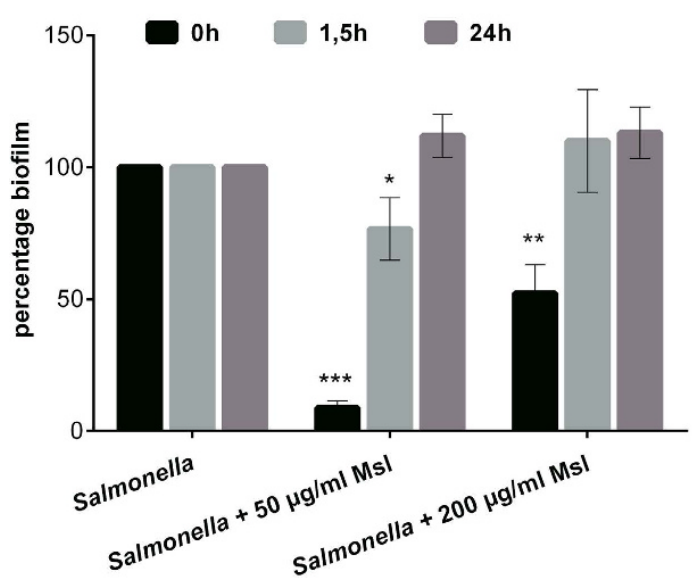

(b)

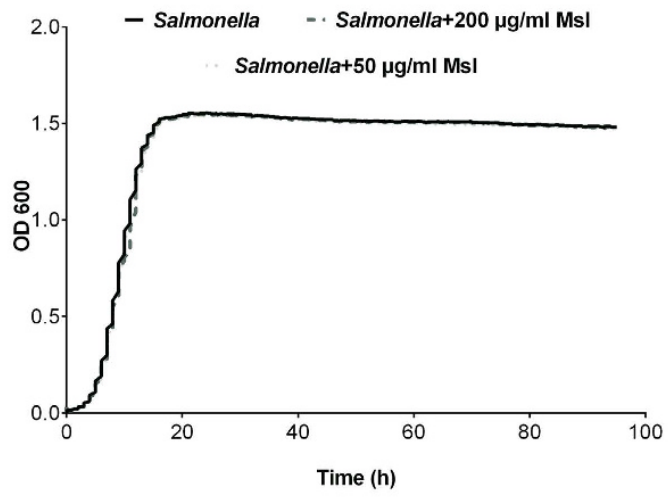

S. Typhimurium + FITC labeled MsI lectin domains

(c)

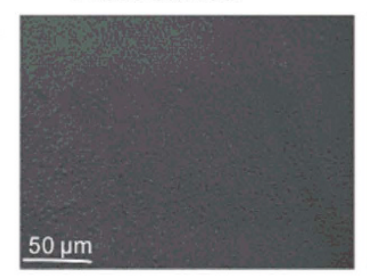

(d)

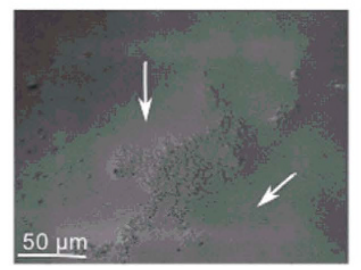

Epifluorescence
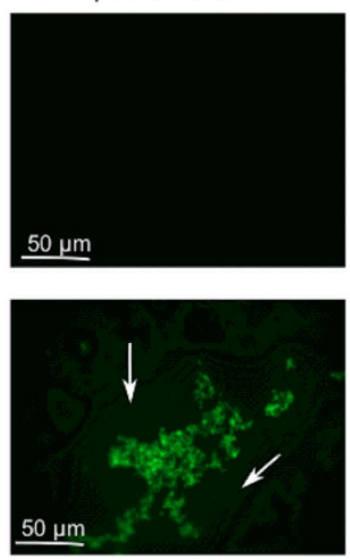

Merged
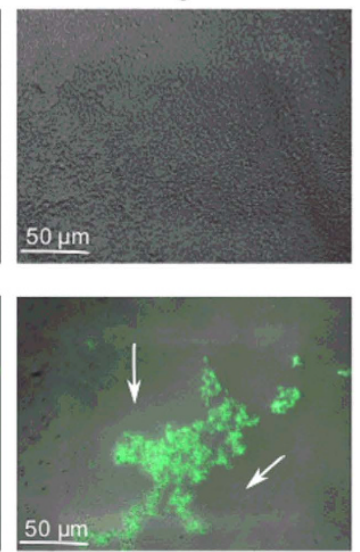

Figure 7. Activity of the lectin domain of Cmpg5300.05_29 against $S$. Typhimurium ATCC14028. (a) Anti-biofilm activity of the lectin domain of Cmpg5300.05_29. The purified lectin domain of Cmpg5300.05_29 was added after 0, 1.5 and $24 \mathrm{~h}$ to the biofilms at $50 \mu \mathrm{g} / \mathrm{ml}$ and $200 \mu \mathrm{g} / \mathrm{ml}$. (b) Growth of $S$. Typhimurium ATCC14028 in presence of lectin domain of Cmpg5300.05_29 added at 50 $\mu \mathrm{g} / \mathrm{ml}$ and $200 \mu \mathrm{g} / \mathrm{ml}$. The dataset comparisons (biofilm formation with addition of lectin to biofilm without adding lectins) are considered significant $(p<0.05$ indicated with one asterisks, $p<0.01$ indicated with two asterisks and $p<0.001$ indicated with three asterisks in the figure). (c) Biofilms of S. Typhimurium ATCC14028 grown in 1/20 TSB (negative control) and (d) with $50 \mu \mathrm{g} / \mathrm{ml}$ of FITC-labeled lectin domain of Cmpg5300.05_29. Holes in biofilms are indicated with arrows.

various bacteria against antibiotics ${ }^{40}$. The Msl lectin, by itself or when present on live lactobacilli, could then have a promising potential for local application for exclusion of high-mannose containing pathogens.

This study is thus of relevance for the use of whole bacterial cells as prophylactic probiotics, since the lectins promote the potential colonization capacity of the strains in the human vagina. The enhanced colonization of these probiotics could in turn prevent adhesion and colonization by pathogens causing vaginal infections. Alternatively, the isolated lectin could be used in therapeutic mode for urogenital as well as gastrointestinal infections, for instance, in synergy with antibiotics to disrupt biofilms that are otherwise difficult to treat only with antibiotics.

\section{Material and Methods}

Bacterial strains and culture conditions. L. plantarum CMPG5300 and its mutant derivatives (Table 2) were routinely grown without agitation in Man Rogosa Sharpe (MRS) (Difco) at $37^{\circ} \mathrm{C}$. For cloning purpose, E. coli TOP10 and BL21/DE3 were grown with shaking at $37^{\circ} \mathrm{C}$ in Luria Bertani (LB) medium. When required, antibiotics were added at the following final concentrations: chloramphenicol, $20 \mu \mathrm{g} / \mathrm{ml}$ for L. plantarum and $10 \mu \mathrm{g} / \mathrm{ml}$ for E. coli; erythromycin, $10 \mu \mathrm{g} / \mathrm{ml}$ for L. plantarum and $250 \mu \mathrm{g} / \mathrm{ml}$ for E. coli; ampicillin $100 \mu \mathrm{g} / \mathrm{ml}$ for $E$. coli and kanamycin $50 \mu \mathrm{g} / \mathrm{ml}$ for E. coli. 


\begin{tabular}{|c|c|c|c|}
\hline Name of the species & Name of the strain & Relevant genotype/description & Reference/source \\
\hline \multicolumn{4}{|l|}{ Bacterial/yeast strains } \\
\hline \multirow{4}{*}{ L. plantarum } & CMPG5300 & Wild type, human vaginal isolate & Malik et al. ${ }^{24}$ \\
\hline & CMPG11201 & $\Delta c m p g 5300.05 \_29:: \mathrm{Cm}^{\mathrm{r}}$ & This study \\
\hline & CMPG11202 & CMPG11201 complemented with $c m p g 5300.05 \_29$ & This study \\
\hline & WCFS1 & $\begin{array}{l}\text { Sequenced wild-type strain; single colony isolate of } \\
\text { NCIMB } 8826 \text { from human saliva }\end{array}$ & 48 \\
\hline \multirow{3}{*}{ E. coli } & TOP10F & $\begin{array}{l}\text { F' (lacIq, Tnr) mcrA_(mrr hsdRMS-mcrBC) 80LacZ } \\
\text { lacX74 deoR recA1 araD139_(araleu) }\end{array}$ & Invitrogen \\
\hline & BL21/DE3 & 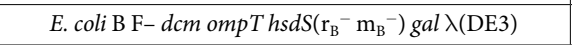 & Invitrogen \\
\hline & UTI89 & Wild type, clinical isolate & 49 \\
\hline P. aeruginosa & PA14 & Wild type, human isolate & 50 \\
\hline S. cerevisiae & BY 4741 & MATa; his $3 \Delta 1 ;$ leu $2 \Delta 0 ;$ met $15 \Delta 0 ;$ ura $3 \Delta 0$ & 51 \\
\hline C. albicans & SC5314 (ATCC MYA-2876) & Wild type, human clinical isolate & 52 \\
\hline \multirow{2}{*}{ S. aureus } & SH1000 & $r s b U$ positive derivative of S. aureus $8325-4$ & 53 \\
\hline & Rosenbach (ATCC 33591) & Wild type, clinical isolate & ATCC \\
\hline \multirow{3}{*}{$\begin{array}{l}\text { S. enterica serovar } \\
\text { Typhimurium }\end{array}$} & ATCC 14028 & Wild type, isolated from chicken tissue & ATCC $^{54}$ \\
\hline & $\begin{array}{l}\text { ATCC } 14028 \text { carrying } \\
\text { pFPV25.1 }\end{array}$ & Mutant constitutively expressing GFP & 46 \\
\hline & Host & Relevant description & Reference/source \\
\hline \multicolumn{4}{|l|}{ Plasmids } \\
\hline pNZ5319 & E. coli & $\begin{array}{l}\text { pNZ5318 derivative for multiple gene replacements in } \\
\text { gram-positive bacteria } \mathrm{Cm}^{\mathrm{r}} \mathrm{Ery}^{\mathrm{r}}\end{array}$ & Lambert et al. ${ }^{42}$ \\
\hline pCMPG10208 & E. coli & pLAB1301 derivative driven by dlt promoter, $\mathrm{Ap}^{\mathrm{r}}, \mathrm{Ery}^{\mathrm{r}}$ & Unpublished results \\
\hline pCMPG11201 & E. coli & $\begin{array}{l}\text { pNZ5319 derivative containing homologous regions up- } \\
\text { and downstream of } c m p g 5300.05 \_29, \mathrm{Cm}^{\mathrm{r}} \text { Ery }\end{array}$ & This study \\
\hline pCMPG11202 & E. coli & $\begin{array}{c}\text { pCMPG10208 derivative containing cmpg5300.05_29 of } \\
\text { CMPG5300, } \mathrm{Ap}^{\mathrm{r}}, \mathrm{Ery}^{\mathrm{r}}\end{array}$ & This study \\
\hline pET28a+ & E. coli & $\mathrm{Kan}^{\mathrm{r}}$, T7 lac, N and C-terminal His Tag & Novagen \\
\hline pCMPG11209 & E. coli & $\begin{array}{l}\text { pET28a + derivative containing the lectin domain of } \\
\text { cmpg5300.05_29 of CMPG5300, } \operatorname{Kan}^{\mathrm{r}}\end{array}$ & This study \\
\hline pCMPG11210 & E. coli & $\begin{array}{l}\text { pET28a }+ \text { derivative containing the lectin domain of } m s a \\
\text { gene of } L \text {. plantarum WCFS } 1, \operatorname{Kan}^{\mathrm{r}}\end{array}$ & This study \\
\hline
\end{tabular}

Table 2. Strains and plasmids used in this study.

E. coli UTI89, P. aeruginosa PA14, S. Typhimurium ATCC14028, S. aureus Rosenbach and SH1000 were grown routinely in LB medium with aeration at $37^{\circ} \mathrm{C}$. C. albicans SC5314 and S. cerevisiae BY4741 were grown in yeast-extract peptone dextrose (YPD) medium ( $2 \%$ peptone, $1 \%$ yeast extract, $2 \%$ glucose) under aerobic conditions at $37^{\circ} \mathrm{C}$.

Identification of cmpg5300.05_29 and Southern hybridization. The genome mining of CMPG5300 and its alignment with L. plantarum WCFS1 in our previous study ${ }^{11}$ led to the identification of cmpg5300.05_29 as a potential lectin-encoding gene of CMPG5300. This gene occurred on contig 54 and is potentially plasmid-encoded. To obtain the complete gene sequence, the gaps were closed by using the primers mentioned in Table S1. Furthermore, as the contig 54 containing the cmpg5300.05_29 gene sequence did not align with the $m s a$ gene of L. plantarum WCFS1 (lp_1229), efforts were made to identify whether the gene was present on the chromosomal DNA or plasmid DNA. For this purpose, Southern hybridization ${ }^{41}$ was performed using the genomic DNA and plasmid DNA isolated from CMPG5300 (Malik et al. ${ }^{24}$ ). The primers used for constructing the probes are listed in supplementary information Table S1.

Construction of cmpg5300.05_29 knock-out mutant. In order to study the role of Cmpg5300.05_29, its gene was knocked out using double homologous recombination using a cre-lox strategy ${ }^{42}$ as described previously for the sortase gene srtA in L. plantarum CMPG5300 ${ }^{24}$. The corresponding plasmids and primers used are mentioned in Table 2 and Table S1, respectively. The mutant, CMPG11201, was selected on the basis of resistance against chloramphenicol and checked by PCR and Southern hybridization. For complementation, cmpg5300.05_29 was amplified using the primers PRO 8367 and PRO 8368 and ligated downstream of the $d l t$ promoter in the vector pCMPG10208 resulting in pCMPG11202. CMPG11201 was complemented with cmpg5300.05_29 by electroporation of pCMPG11202 resulting in strain CMPG11202. To validate gene complementation, qRT-PCR was performed as done for CMPG5376 (Malik et al. ${ }^{24}$ ) using primers mentioned in Table S1.

Heterologous expression and purification of lectin domain of Cmpg5300.05_29. The recombinant E. coli (BL21/DE3) (Table 2) expressing the lectin domains of Cmpg5300.05_29 (plasmid pCMPG11209) and Msa of L. plantarum WCFS1 (pCMPG11210) were grown overnight in LB with $50 \mu \mathrm{g} / \mathrm{ml}$ kanamycin. Each culture was diluted 100 -fold in 2 liter LB with kanamycin and grown for 2 to $3 \mathrm{~h}$ at $37^{\circ} \mathrm{C}$ under agitation until 
an optical density (OD) $(595 \mathrm{~nm})$ between 0.3 and 0.4 was reached. Then the production of recombinant lectin domain was induced with $1 \mathrm{mM}$ isopropyl $\beta$-D-1-thiogalactopyranoside (IPTG) (Sigma-Aldrich). The next day, the pellets were suspended in $20 \mathrm{ml}$ of non-denaturing lysis buffer (Sodium dihydrogen phosphate $50 \mathrm{mM}$, Sodium chloride $300 \mathrm{mM}$, Imidazole $10 \mathrm{mM}, \mathrm{pH}$ 8) per liter of original culture and incubated for $30 \mathrm{~min}$ at room temperature (RT) with gentle swirling. Subsequently the cell lysate was sonicated during $4 \mathrm{~min}$ in cycles of $30 \mathrm{sec}$ on and $30 \mathrm{sec}$ off (amplitude 18\%) to release the soluble recombinant lectin domain from the cells. Subsequently, affinity chromatography was used to purify the lectin domains. Hereto, the lysate was first filtered with $0.2 \mu \mathrm{M}$ filters and the filtered lysate was run through a HisTrapTM HP column (GE Healthcare). Different fractions were collected and sample purity was analyzed through sodium dodecyl sulfate-polyacrylamide gel electrophoresis (SDS-PAGE). The lectin domains were further purified from the eluted sample using size exclusion chromatography, using a HighloadTM 16/60 column packed with a matrix of SuperdexTM prep grade (GE Healthcare). Fractions containing the purified lectin domains were collected, analyzed using SDS-PAGE and Western Blotting (with primary mouse monoclonal anti-His6 antibodies), pooled together and concentrated.

In vitro adhesion and biofilm formation. To assess the role of Cmpg5300.05_29 in adhesion of the strain to the vaginal epithelial cell line VK2/E6E7 and in biofilm formation on polystyrene, CMPG5300 and its mutant derivatives were analyzed using the adhesion and biofilm assays described previously (Malik et al. ${ }^{24}$ ).

Briefly the adherence of $L$. plantarum CMPG5300 strains to the epithelial cells was examined by adding $1.5 \mathrm{ml}$ of DMEM containing $10^{7} \mathrm{CFU} / \mathrm{ml}$. After incubation at $37^{\circ} \mathrm{C}$ for $1 \mathrm{~h}$, epithelial cells were washed twice with pre-warmed PBS. Subsequently, $100 \mu \mathrm{l}$ of trypsin-EDTA (1x) (Invitrogen) was added to each well and incubated for $10 \mathrm{~min}$ at $37^{\circ} \mathrm{C}$. Finally, $900 \mu \mathrm{l}$ of PBS was added, mixed and serial dilutions were plated out on MRS plates. Alternatively, a fluorescence assay was performed as described previously ${ }^{19}$ with minor modifications. The FITC labelled lectin domain of Cmpg5300.05_29 was suspended in the DMEM medium in the absence of serum and antibiotics, and incubated for $1 \mathrm{~h}$ with the monolayers of VK2/E6E7 cells grown on 13-mm coverslips. After incubation, the cells were washed three times with PBS, and fixed with $4 \%$ paraformaldehyde for $10 \mathrm{~min}$. Slides were examined with a Zeiss Axio Imager Z1 microscope using an EC Plan Neofluar (X40 magnification/0.3 numerical aperture) objective (excitation $488 \mathrm{~nm}$, emission $511 \mathrm{~nm}$ ). Pictures were acquired with an AxioCam MRm and the AxioVision.

Mannose-dependent S. cerevisiae and C. albicans agglutination assay. A yeast agglutination assay was performed using the protocol described previously (Pretzer et al. ${ }^{12}$ ) but with minor modifications. Briefly, overnight-grown cultures of Lactobacillus strains were washed, suspended in phosphate buffered saline (PBS, $\mathrm{pH}$ 7.2) to a final concentration of $1 \times 10^{10} \mathrm{CFUs} / \mathrm{ml}$. Similarly, overnight cultures of S. cerevisiae or C. albicans cells were washed and suspended in PBS so as to a make a $1 \% \mathrm{w} / \mathrm{v}$ cell suspension. For agglutination, $25 \mu \mathrm{l}$ of bacterial suspension was added to $25 \mu \mathrm{l}$ of PBS followed by $50 \mu \mathrm{l}$ of yeast cells suspension in a 96 -well U-bottom well sterile plate (Greiner bio-one). The mixtures were incubated for $10 \mathrm{~min}$ at RT with gentle shaking. To study inhibition, $25 \mu \mathrm{l}$ of methyl- $\alpha$-D-mannopyranoside $(50 \mathrm{mM}$; Sigma-Aldrich) was added to the bacterial suspension instead of PBS. To examine agglutination, the mixtures were spotted on a slide and viewed under a phase-contrast microscope (400-fold magnification, Zeiss Axio Imager Z1 microscope equipped with an AxioCam MRm Rev.3 monochrome digital camera). Alternatively C. albicans and S. cerevisiae were incubated with $200 \mu \mathrm{g} / \mathrm{ml}$ of fluorescein isothiocyanate (FITC)-labeled lectin domain of Cmpg5300.05_29 alone and in combination with $25 \mu \mathrm{l}$ of methyl- $\alpha$-D-mannopyranoside (50 mM; Sigma-Aldrich). As a control, a lectin L-type domain of lectin-like protein 2 (Llp2) from L. rhamnosus GG was used.

ELISA-based assay for assessing sugar binding. For a quantitative analysis of mannan binding, an ELISA-based assay (Velez et al. ${ }^{43}$ ) was used with minor modifications. The microtiter (X50 Immulon 4HBX 96 well plates, Fischer Scientific) plate was coated with $10 \mu \mathrm{g}$ mannan from S. cerevisiae (Sigma Aldrich NV) or Bovine Serum Albumin (BSA) (Sigma Aldrich NV) (negative control) per well prepared in carbonate-bicarbonate buffer ( $\mathrm{pH} 9.6$ ) and incubated overnight at $4^{\circ} \mathrm{C}$. Overnight cultures of Lactobacillus strains were washed twice with PBS and suspended in $0.1 \mathrm{M}$ carbonate buffer ( $\mathrm{pH}$ 8.2) up to a final concentration of $1 \times 10^{10} \mathrm{CFUs} / \mathrm{ml}$. For labeling the cells, biotin $N$-hydroxysuccinimide ester (Sigma) was added to the cells at a concentration of $100 \mu$ $\mathrm{g} / \mathrm{ml}$ and the cells were incubated at RT for $1 \mathrm{~h}$ with gentle swirling. Subsequently, the wells were washed with distilled water and blocked with blocking buffer (TBSt 20 with $0.5 \%$ blocking agent) for $2 \mathrm{~h}$ at RT. Simultaneously, the biotin-labelled cells were washed thrice with PBS and suspended in PBS so as to make a working concentration of $2.5 \times 10^{9} \mathrm{CFUs} / \mathrm{ml}$. The cells were added to the pre-coated wells which were then washed with PBS and incubated for $1 \mathrm{~h}$ at $37^{\circ} \mathrm{C}$. Subsequently, the plate was washed with PBST (PBS with $0.025 \%$ Tween 20) to remove unbound cells. Color was developed by adding Alkaline Phosphatase (AP)-Strep (1:5000 in blocking buffer) in each well for $1 \mathrm{~h}$ at $37^{\circ} \mathrm{C}$. The plate was washed and 4-nitrophenyl phosphate (NPP) disodium salt (Sigma; $1 \mathrm{mg} /$ $\mathrm{ml}$ in carbonate bicarbonate buffer) was added as the substrate. Color was allowed to develop for 15-30 min at RT and the absorbance was read at $405 \mathrm{~nm}$. The experiments were performed at least three times with six technical repeats each.

Pull-down sugar binding assays using Sepharose beads. Sepharose ${ }^{\circledR}$ 6B beads (Sigma-Aldrich) were coated with $20 \% \mathrm{D}$-glucose, GlcNac, D-mannose, D-fucose and mannan of S. cerevisiae, as previously described ${ }^{44,45}$ with minor modifications. For the sugar-binding assay, $25 \mu$ l of each set of coated functionalized beads was washed with binding buffer as previously described ${ }^{45} .1 \mathrm{ml}$ of binding buffer containing $50 \mu \mathrm{g}$ of the purified lectin domain of Cmpg5300.05_29 was added to each set of beads. Hereafter, the mixtures were incubated for $2 \mathrm{~h}$ at $4^{\circ} \mathrm{C}$. The beads were washed twice with $1 \mathrm{ml}$ of wash buffer and bound samples of lectin domain were eluted by boiling the beads in SDS-PAGE loading buffer (Fermentas, Life Sciences) for $10 \mathrm{~min}$ at $95^{\circ} \mathrm{C}$. 
The eluates were resolved by SDS-PAGE through $12 \%$ polyacrylamide gels (Life Sciences), which were stained with Sypro ${ }^{\circledR}$ Ruby protein gel stain (Invitrogen) and scanned using the Typhoon scanner (GE Healthcare Life Sciences).

Glycan array analysis. To test a larger number of glycosylated substrates, the purified lectin domain was subsequently sent for glycan array screening at the Consortium for Functional Glycomics (CFG). The mammalian glycan array version 5.2 was used to determine the exact sugar specificity of the lectin domain. The array consists of 609 glycan targets of natural and synthetic mammalian glycans with amino linkers and is printed onto N-hydroxysuccinimide (NHS)-activated glass microscope slides (SCHOTT Nexterion), forming covalent amide linkages. The purified sample (lectin domain of Cmpg5300.05_29) was labeled with FITC by using FluoReporter ${ }^{\circledR}$ FITC Protein Labeling Kit (Life Technologies) according to the producer's manual. Two different concentrations of FITC labeled protein, namely $20 \mu \mathrm{g} / \mathrm{ml}$ and $200 \mu \mathrm{g} / \mathrm{ml}$, were used to determine the exact sugar-binding capacity. The experiment was then performed by the Consortium for Functional Glycomics (CFG, www.functionalglycomics.org).

HIV-1 gp120 and gp41 binding assay via ELISA and SPR analysis. To determine the role of Cmpg5300.05_29 in binding to HIV-1 envelope glycoprotein gp120 and gp41, the cells of L. plantarum CMPG5300 and $m s l$ mutant strain CMPG11201 were labeled with biotin, incubated with $2 \mu \mathrm{g} / \mathrm{ml}$ immobilized HIV-1 gp120 or gp41 (ImmunoDiagnostics Inc., Woburn, MA) (produced by CHO cell cultures) and assessed for binding using the ELISA-based method described above for mannan.

Furthermore, binding of the lectin domain was assessed by SPR analysis using the method described previously (Balzarini et al. ${ }^{16}$ ). Briefly, recombinant gp120 protein from HIV-1 strain IIIB and recombinant gp41 protein from HIV-1 (HXB2 strain) (Acris Antibodies GmbH, Herford, Germany) (produced by Pichia pastoris) were covalently immobilized on the carboxymethylated dextran matrix of a CM4 sensor chip in $10 \mathrm{mM}$ sodium acetate, $\mathrm{pH}$ 5.0, using standard amine coupling chemistry at final densities of 115 RUs and 45 RUs, respectively. In another set of experiments, binding of the lectin domain to gp120 and gp41 was subjected to a detailed kinetic characterization. A 1:1 fit was applied to obtain the association rate constant $(\mathrm{ka})$, the dissociation rate constant $(k d)$, and the apparent kinetic rate constant $\left(K_{D}\right)$. All interaction studies were performed at $25^{\circ} \mathrm{C}$ on a Biacore T200 instrument (GE Healthcare, Uppsala, Sweden) in HBS-P (10 mM HEPES, $150 \mathrm{mM} \mathrm{NaCl}$ and $0.05 \%$ surfactant $\mathrm{P} 20 ; \mathrm{pH}$ 7.4) containing $10 \mathrm{mM} \mathrm{CaCl}_{2}$. The $\mathrm{CM} 4$ sensor chip surface was regenerated with a single injection of $50 \mathrm{mM} \mathrm{NaOH}$.

HIV-1 inhibition assays. The inhibitory activity of purified lectin domain against HIV-1( III $_{B}$ )- and HIV2-induced cytopathicity in C8166 and Raji DCSIGN cell cultures was examined in microtiter 96-well plates containing $\sim 3 \times 10^{5}$ cells $/ \mathrm{ml}$ infected with $100 \mathrm{CCID}_{50}$ of HIV per $\mathrm{ml}$ and appropriate dilutions of the test samples. After 4-5 days of incubation at $37^{\circ} \mathrm{C}, \mathrm{C} 8166$-induced giant (syncytium) cell formation was examined microscopically and the $50 \%$ effective concentrations $\left(\mathrm{EC}_{50}\right)$ determined.

Antimicrobial assays for interference with pathogen grown in suspension. In order to verify whether the lectin domain of Cmpg5300.05_29 affects the growth of pathogens, bioscreen experiments were performed. Overnight cultures of S. aureus SH1000, S. aureus Rosenbach, E. coli UTI89, and S. Typhimurium ATCC14028 were diluted 200-fold in Tryptic Soy Broth (TSB) medium and $200 \mu \mathrm{l}$ of cell suspensions were added to sterile wells of 100-well microtiter plates (Honeycomb, Oy Growth Curves Ab Ltd). The purified lectin domain of Cmpg5300.05_29 was added at concentrations of $50 \mu \mathrm{g} / \mathrm{ml}$ and $200 \mu \mathrm{g} / \mathrm{ml}$. These were incubated at $37^{\circ} \mathrm{C}$ for 3 days under continuous agitation in a Bioscreen (Oy Growth Curves Ab Ltd), which measured the OD at $600 \mathrm{~nm}$ every $10 \mathrm{~min}$ to monitor growth. TSB was used as blank. Each strain and concentration of the sample containing lectin domain was tested in triplicate.

Antimicrobial assays for interference with pathogen growth in biofilms. The static peg biofilm assays were performed as described previously with minor modifications ${ }^{46,47}$. Hereto, E. coli UTI89, P. aeruginosa PA14, S. aureus SH1000, S. aureus Rosenbach and S. Typhimurium ATCC14028 were grown in the presence of 50 or $200 \mu \mathrm{g} / \mathrm{ml}$ of lectin domain of Cmpg5300.05_29. After $48 \mathrm{~h}$ of incubation, biofilm formation was quantified by coloring with crystal violet $(0.1 \% \mathrm{w} / \mathrm{v}$ in $5 \%$ methanol, $5 \%$ isopropanol and $90 \% \mathrm{PBS})$. For each strain and concentration tested, the experiment was performed at least three times with eight technical repeats. Alternatively, the lectin domain of Cmpg5300.05_29 was added after 1.5 h (the initial adhesion phase of the tested pathogens). In a third version of the assay, the sample was added with fresh medium after $24 \mathrm{~h}$ to investigate if the lectin domain could disrupt an already established biofilm.

For the visualization of E. coli UTI89 and S. Typhimurium biofilms the FITC- labeled lectin domain of Cmpg5300.05_29 was added at the onset of the biofilm formation $(\mathrm{t}=0 \mathrm{~h})$ at $50 \mu \mathrm{g} / \mathrm{ml}$ concentration and the biofilms were grown for $48 \mathrm{~h}$. Microscopic epifluorescent imaging was performed using a Zeiss Axio Imager Z1 microscope with an EC Plan Neofluar (X40 magnification/0.3 numerical aperture) objective (excitation $488 \mathrm{~nm}$, emission $511 \mathrm{~nm}$ ). Pictures were acquired with an AxioCam MRm and the AxioVision software.

Statistical analysis. To determine significant differences the unequal variance t-test was applied. A P-value below 0.05 was considered as statistically significant.

\section{References}

1. Reid, G. et al. Microbes central to human reproduction. Am. J. Reprod. Immunol. 73, 1-11 (2015).

2. Petrova, M. I., Lievens, E., Malik, S., Imholz, N. \& Lebeer, S. Lactobacillus species as biomarkers and agents that can promote various aspects of vaginal health. Front Physiol 6, 81 (2015). 
3. Petrova, M. I., van den, B. M., Balzarini, J., Vanderleyden, J. \& Lebeer, S. Vaginal microbiota and its role in HIV transmission and infection. FEMS Microbiol Rev. 37, 762-792 (2013).

4. Dimitonova, S. P., Danova, S. T., Serkedjieva, J. P. \& Bakalov, B. V. Antimicrobial activity and protective properties of vaginal lactobacilli from healthy Bulgarian women. Anaerobe. 13, 178-184 (2007).

5. Atassi, F., Brassart, D., Grob, P., Graf, F. \& Servin, A. L. Lactobacillus strains isolated from the vaginal microbiota of healthy women inhibit Prevotella bivia and Gardnerella vaginalis in coculture and cell culture. FEMS Immunol. Med. Microbiol. 48, 424-432 (2006).

6. Otero, M. C. \& Nader-Macias, M. E. Inhibition of Staphylococcus aureus by $\mathrm{H}_{2} \mathrm{O}_{2}$-producing Lactobacillus gasseri isolated from the vaginal tract of cattle. Anim Reprod. Sci. 96, 35-46 (2006).

7. Murina, F., Graziottin, A., Vicariotto, F. \& De, S. F. Can Lactobacillus fermentum LF10 and Lactobacillus acidophilus LA02 in a slowrelease vaginal product be useful for prevention of recurrent vulvovaginal candidiasis?: A clinical study. J. Clin. Gastroenterol. 48, S102-S105 (2014).

8. Han, C. et al. Diagnostic and therapeutic advancements for aerobic vaginitis. Arch. Gynecol. Obstet. 291, 251-257 (2015).

9. Razzak, M. S., Al-Charrakh, A. H. \& Al-Greitty, B. H. Relationship between lactobacilli and opportunistic bacterial pathogens associated with vaginitis. N. Am. J. Med. Sci. 3, 185-192 (2011).

10. Hooper, L. V. \& Gordon, J. I. Glycans as legislators of host-microbial interactions: spanning the spectrum from symbiosis to pathogenicity. Glycobiology 11, 1R-10R (2001)

11. Malik, S. et al. Draft Genome Sequence of Lactobacillus plantarum CMPG5300, a Human Vaginal Isolate. Genome Announc. 2, e01149-14 (2014).

12. Pretzer, G. et al. Biodiversity-based identification and functional characterization of the mannose-specific adhesin of Lactobacillus plantarum. J. Bacteriol. 187, 6128-6136 (2005).

13. Gross, G., Snel, J., Boekhorst, J., Smits, M. A. \& Kleerebezem, M. Biodiversity of mannose-specific adhesion in Lactobacillus plantarum revisited: strain-specific domain composition of the mannose-adhesin. Benef. Microbes. 1, 61-66 (2010).

14. Mirelman, D., Altmann, G. \& Eshdat, Y. Screening of bacterial isolates for mannose-specific lectin activity by agglutination of yeasts. J. Clin. Microbiol. 11, 328-331 (1980).

15. Mangold, S. L. \& Cloninger, M. J. Binding of monomeric and dimeric Concanavalin A to mannose-functionalized dendrimers. Org. Biomol. Chem. 4, 2458-2465 (2006).

16. Balzarini, J. Targeting the glycans of glycoproteins: a novel paradigm for antiviral therapy. Nat. Rev. Microbiol. 5, 583-597 (2007).

17. Topin, J. et al. Deciphering the glycan preference of bacterial lectins by glycan array and molecular docking with validation by microcalorimetry and crystallography. PLoS. One. 8, e71149 (2013).

18. Wellens, A. et al. The tyrosine gate as a potential entropic lever in the receptor-binding site of the bacterial adhesin FimH. Biochemistry. 19, 4790-4799 (2012).

19. Yang, Y. H. et al. Structural insights into SraP-mediated Staphylococcus aureus adhesion to host cells. PLoS. Pathog. 10, e1004169 (2014).

20. Desmond, C., Ross, R. P., Fitzgerald, G. \& Stanton, C. Sequence analysis of the plasmid genome of the probiotic strain Lactobacillus paracasei NFBC338 which includes the plasmids pCD01 and pCD02. Plasmid 54, 160-175 (2005).

21. Erhardt, M. \& Dersch, P. Regulatory principles governing Salmonella and Yersinia virulence. Front Microbiol. 6, 949 (2015).

22. Boris, S., Suarez, J. E., Vazquez, F. \& Barbes, C. Adherence of human vaginal lactobacilli to vaginal epithelial cells and interaction with uropathogens. Infect Immun. 66, 1985-1989 (1998).

23. Gil, N. F., Martinez, R. C., Gomes, B. C., Nomizo, A. \& De Martinis, E. C. Vaginal lactobacilli as potential probiotics against Candida SPP. Braz. J. Microbiol. 41, 6-14 (2010).

24. Malik, S. et al. The high auto-aggregative and adhesive phenotype of the vaginal Lactobacillus plantarum strain CMPG5300 is sortase-dependent. Appl. Environ. Microbiol. doi: 10.1128/AEM.00926-13 (2013).

25. Boris, S., Suarez, J. E. \& Barbes, C. Characterization of the aggregation promoting factor from Lactobacillus gasseri, a vaginal isolate. J. Appl. Microbiol. 83, 413-420 (1997).

26. Kwok, L. et al. Adherence of Lactobacillus crispatus to vaginal epithelial cells from women with or without a history of recurrent urinary tract infection. J. Urol. 176, 2050-2054 (2006).

27. Balzarini, J. Targeting the glycans of gp120: a novel approach aimed at the Achilles heel of HIV. Lancet Infect. Dis. 5, 726-731 (2005).

28. Francois, K. O. \& Balzarini, J. Potential of carbohydrate-binding agents as therapeutics against enveloped viruses. Med. Res. Rev. 32, 349-387 (2012).

29. Linhares, I. M., Giraldo, P. C. \& Baracat, E. C. New findings about vaginal bacterial flora. Rev. Assoc. Med. Bras. 56, 370-374 (2010).

30. Herrera, C. et al. Nonneutralizing antibodies to the CD4-binding site on the gp 120 subunit of human immunodeficiency virus type 1 do not interfere with the activity of a neutralizing antibody against the same site. J. Virol. 77, 1084-1091 (2003).

31. Hatziioannou, T. \& Evans, D. T. Animal models for HIV/AIDS research. Nat. Rev. Microbiol. 10, 852-867 (2012).

32. Petit, N. \& Marodon, G. Lessons from HIV-1 gene therapy in humanized mice: is targeting viral entry the road to success? Curr. Gene Ther. 16, 56-64 (2016).

33. Tenke, P. et al. Update on biofilm infections in the urinary tract. World J. Urol. 30, 51-57 (2012).

34. McMillan, A. et al. Disruption of urogenital biofilms by lactobacilli. Colloids Surf. B Biointerfaces. 86, 58-64 (2011).

35. Saunders, S., Bocking, A., Challis, J. \& Reid, G. Effect of Lactobacillus challenge on Gardnerella vaginalis biofilms. Colloids Surf. B Biointerfaces. 55, 138-142 (2007).

36. Woo, J. \& Ahn, J. Probiotic-mediated competition, exclusion and displacement in biofilm formation by food-borne pathogens. Lett. Appl. Microbiol. 56, 307-313 (2013).

37. Flemming, H. C. \& Wingender, J. The biofilm matrix. Nat. Rev. Microbiol. 8, 623-633 (2010).

38. Steenackers, H., Hermans, K., Vanderleyden, J. \& De Keersmaecker, S. C. J. Salmonella biofilms: An overview on occurrence, structure, regulation and eradication. Food Research Internationa 45, 502-531. (2012).

39. Van, H. R. \& Michiels, C. W. Role of bacterial cell surface structures in Escherichia coli biofilm formation. Res. Microbiol. 156, 626-633 (2005).

40. Berendonk, T. U. et al. Tackling antibiotic resistance: the environmental framework. Nat. Rev. Microbiol. 13, 310-317 (2015).

41. Sambrook, J., Fritsch, E. F. \& Maniatis, T. Molecular cloning: a laboratory manual. (eds Sambrook, J. \& Russell, D. W.) (1989).

42. Lambert, J. M., Bongers, R. S. \& Kleerebezem, M. Cre-lox-based system for multiple gene deletions and selectable-marker removal in Lactobacillus plantarum. Appl. Environ. Microbiol. 73, 1126-1135 (2007).

43. Velez, M. P. et al. Characterization of MabA, a modulator of Lactobacillus rhamnosus GG adhesion and biofilm formation. FEMS Immunol. Med. Microbiol. 59, 386-398 (2010).

44. Fornstedt, N. \& Porath, J. Characterization studies on a new lectin found in seeds of Vicia ervilia. FEBS Lett. 57, 187-191 (1975).

45. Cash, H. L., Whitham, C. V., Behrendt, C. L. \& Hooper, L. V. Symbiotic bacteria direct expression of an intestinal bactericidal lectin. Science 313, 1126-1130 (2006).

46. Robijns, S. C. et al. A GFP promoter fusion library for the study of Salmonella biofilm formation and the mode of action of biofilm inhibitors. Biofouling. 30, 605-625 (2014).

47. Steenackers, H. P. et al. Structure-activity relationship of 4(5)-aryl-2-amino-1H-imidazoles, N1-substituted 2-aminoimidazoles and imidazo[1,2-a]pyrimidinium salts as inhibitors of biofilm formation by Salmonella typhimurium and Pseudomonas aeruginosa. J. Med. Chem. 54, 472-484 (2011). 
48. Kleerebezem, M. et al. Complete genome sequence of Lactobacillus plantarum WCFS1. Proc. Natl. Acad. Sci. USA 100, 1990-1995 (2003).

49. Hunstad, D. A., Justice, S. S., Hung, C. S., Lauer, S. R. \& Hultgren, S. J. Suppression of bladder epithelial cytokine responses by uropathogenic Escherichia coli. Infect. Immun. 73, 3999-4006 (2005).

50. Rahme, L. G. et al. Common virulence factors for bacterial pathogenicity in plants and animals. Science 268, 1899-1902 (1995).

51. Brachmann, C. B. et al. Designer deletion strains derived from Saccharomyces cerevisiae S288C: a useful set of strains and plasmids for PCR-mediated gene disruption and other applications. Yeast 14, 115-132 (1998).

52. Gillum, A. M., Tsay, E. Y. \& Kirsch, D. R. Isolation of the Candida albicans gene for orotidine- $5^{\prime}$-phosphate decarboxylase by complementation of S. cerevisiae ura3 and E. coli pyrF mutations. Mol. Gen. Genet. 198, 179-182 (1984).

53. Horsburgh, M. J. et al. sigmaB modulates virulence determinant expression and stress resistance: characterization of a functional rsbU strain derived from Staphylococcus aureus 8325-4. J. Bacteriol. 184, 5457-5467 (2002).

54. Fields, P. I., Swanson, R. V., Haidaris, C. G. \& Heffron, F. Mutants of Salmonella typhimurium that cannot survive within the macrophage are avirulent. Proc. Natl. Acad. Sci. USA 83, 5189-5193 (1986).

\section{Acknowledgements}

We thank David De Coster and Stefanie Roberfroid from CMPG, KU Leuven, Leuven, Belgium for their technical assistance with Salmonella biofilms and with the fluorescence microscope. We also acknowledge Prof. R. J. Siezen and Dr. B. Renckens from the Centre for Molecular and Biomolecular Informatics (CMBI) of the Radboud University in Nijmegen for their help with the genome analysis of L. plantarum CMPG5300. SM was supported by the KU Leuven (PF 10/18) and Erasmus Mundus. MP holds a postdoctoral grant from the Fund for Scientific Research (FWO Vlaanderen). SLe was supported from the FWO Vlaanderen with a postdoctoral grant and a research grant $1520114 \mathrm{~N}$. Work at KU Leuven was supported by BOF program financing (PF/10/018, JB, SLi, JVDL, SLe and DS), the GOA (15/19 TBA), and the FWO Vlaanderen (G-0528-12N). Work at UAntwerpen was supported by BOF and IOF-SBO funding. We thank the Protein-glycan Interaction Resource of the CFG and the supporting grant R24 GM098791 for conducting the glycan array analysis.

\section{Author Contributions}

S.M., M.I.P. and S.Le designed the research and wrote the manuscript. S.M., M.I.P., N.I., T.V. and S.N. performed the experimental work. E.V.D. provided guidance for the glycan array analysis. J.B., S.Le, S.Li, D.S. and J.V. guided part of the work and reviewed the manuscript.

\section{Additional Information}

Supplementary information accompanies this paper at http://www.nature.com/srep

Competing financial interests: The authors declare no competing financial interests.

How to cite this article: Malik, S. et al. High mannose-specific lectin Msl mediates key interactions of the vaginal Lactobacillus plantarum isolate CMPG5300. Sci. Rep. 6, 37339; doi: 10.1038/srep37339 (2016).

Publisher's note: Springer Nature remains neutral with regard to jurisdictional claims in published maps and institutional affiliations.

(c) (i) This work is licensed under a Creative Commons Attribution 4.0 International License. The images or other third party material in this article are included in the article's Creative Commons license, unless indicated otherwise in the credit line; if the material is not included under the Creative Commons license, users will need to obtain permission from the license holder to reproduce the material. To view a copy of this license, visit http://creativecommons.org/licenses/by/4.0/

(c) The Author(s) 2016 